\title{
Improved Voltage Boundary with Model-Based Control Algorithm for Increased Torque in the Field Weakening Region of Induction Machines
}

\author{
Hamidreza Gashtil*, Volker Pickert*, Member, IEEE, David John Atkinson*, Mohamed \\ Dahidah", Senior Member, IEEE, Damian Giaouris*, Member, IEEE \\ * School of Engineering, Newcastle University, England, United Kingdom, \\ Phone: +44 (0)1912086684 \\ Fax: +44 (0)191208 8180 \\ E-mail: h.gashtil@ newcastle.ac.uk (Corresponding author), volker.pickert@ newcastle.ac.uk, \\ dave.atkinson@newcastle.ac.uk, damian.giaouris@newcastle.ac.uk, mohamed.dahidah@newcastle.ac.uk
}

\begin{abstract}
At high speed, electric vehicles (EVs) have limited torque when powered by an induction machine (IM). In IM the high-speed region is called field weakening and the region is known for torque limitation. This paper proposes a control method that increases the torque without applying discontinuous-modulation techniques which is commonly used. A bespoke model-based voltage control method has been developed that enables reaching the hexagonal voltage reference trajectory for the field weakening region. So far, all model-based control methods are constrained by the inscribed voltage circle which lies within the hexagonal voltage boundary. This restriction limits the available inverter output voltage across the motor windings, which in turns restricts the output torque of the drive. To achieve the hexagonal voltage trajectory, this paper introduces a new calculation of the d-axis current for the entire speed range in field weakening region. This calculation is based on the hexagonal voltage boundary equations and the stator voltage vector position. This generates a new reference $d$-axis current that minimizes the difference between the hexagonal voltage boundary and its inscribed voltage circle. As a result, the proposed d-axis current maximizes the output torque and output power in the field weakening region. The proposed method is presented analytically. Simulation and experimentally validated results are presented to confirm its feasibility and effectiveness.
\end{abstract}

Index Terms - Flux weakening, induction motor drives, model-based voltage control.

\section{INTRODUCTION}

Today, most electric vehicles (EVs) are either propelled by permanent magnet machines (PMMs) or by induction machines (IMs). IMs have the advantages to be cheaper but must build bigger compared to PMMs to produce the same power.
Extracting the maximum torque from an induction machine (IM) over the entire speed range is of prime importance for traction drives [1]. At high speeds IMs operate in the field weakening region that is known to have torque limitation. Maintaining a high flux within high speed region is important for the production of optimum torque [2,3]. However, high flux levels in the high speed region produces large back EMF which cannot be supported by the inverter output voltage [4]. Therefore, designing a suitable reference flux signal, which produces the maximum torque in accordance with the available battery voltage, is becoming a research trend in traction drive applications [5].

In the literature four different control algorithms for IM machines that generate reference flux in the field weakening region have been proposed. In the following they are called reciprocal speed algorithm, voltage detection algorithm, modelbased algorithm and look-up table, All four algorithms produce the command for the flux-producing current $\left(i_{d s}^{e *}\right)$ which determines the reference flux and each algorithm produces $i_{d s}^{e *}$ differently based on the considered control parameter. Selection of the appropriate reference flux is a key consideration in drive applications which are limited by voltage and current constraints [2].

In the reciprocal speed algorithm, the d-axis rotor flux $\left(\lambda_{d r}^{e}\right)$ in rotor flux oriented (RFO) frame is the control parameter. Often, the command d-axis flux $\left(\lambda_{d r}^{e *}\right)$ is based on the inverse value of rotor speed $\left(w_{r}\right)$ in the field weakening region for conventional IM drives [6]. However, the maximum torque capability of the machine cannot be attained [4]. While, an improvement of torque in the field weakening region can be achieved by employing stator field oriented (SFO) scheme, where the stator flux is changing proportional to inverse of $\omega_{r}$ [7]. However, the derived desired current in SFO cannot be delivered at high speed operation due to the limited inverter voltage [8]. Therefore, the stator current is forced to drop to ensure that the reference voltage does not exceed the normal space vector modulation (SVM) voltage region. This reduction in current leads to a corresponding reduction in motor torque. 
To compensate for the voltage limitation, the voltage detection algorithm was proposed in [9]. In this method, the $i_{d s}^{e *}$ is generated by comparing the maximum available voltage in SVM and the magnitude of the synchronous voltage vector [9]. As the reference voltage is limited to $\frac{V_{D C}}{\sqrt{3}}$ with this algorithm, the full utilization of the DC-link voltage $\left(V_{D C}\right)$ cannot be achieve [10]. An alternative method was proposed in [11], which compares the switching period $T_{Z}$ and the summation of the SVM active switching periods $T_{A}$ and $T_{B}$ to create $i_{d s}^{e *}$. Although this method is able to utilize the full $V_{D C}$ for the electrical machine, at least three PI controllers and a digital filter must be used which makes the tuning of the drive difficult. More details about voltage detection algorithms can be found in [11] and [12].

The third algorithm, called model-based algorithm, derives the voltage and current equations of the IM in the synchronous frame to define $i_{d s}^{e *}[13,14]$. The model requires voltage and current limitations to satisfy the constraints at any specific speed [5, 6]. In addition, the model reflects acceleration and deceleration performance. Consequently, a flux controller based on the machine model is required in order to produce the desired $i_{d s}^{e *}$ during fast acceleration and deceleration of the motor [15]. Furthermore, as a result of calculating the $i_{d s}^{e *}$ based on the machine model, this method is sensitive to the magnetizing inductance $\left(L_{m}\right)[16,17]$. However, this is true as long as the variation of the magnetizing current $\left(i_{m}\right)$ in the field weakening region is high [18]. Therefore, a lookup table of $L_{m}$ based on $i_{m}$ must be used, otherwise variations of $L_{m}$ can be neglected for the model-based algorithm. A limitation of this algorithm is that the stator voltage vector is constrained to lie inside the inscribed voltage circle within the hexagonal voltage boundary and therefore the maximum output voltage is not available [6].

The final algorithm method to generate reference flux in the field weakening region is the lookup table algorithm that defines $i_{d s}^{e *}$ from a look-up table. The reference torque signal $T_{e}^{*}$, that is based on the $w_{r}$, and the null switching time $T_{0}$ of SVM are the key indexes for determining the reference current value $[19,20]$. Using this method retains the maximum torque regardless of variation of $V_{D C}$ [11]. However, developing the efficient look-up table requires the use of high precision measurement devices. In addition, a long time period of experimental tests is required to generate the data for the table.

All four algorithms can be advanced by adding expert controllers which have recently been researched. These expert controllers are placed before the current regulators to avoid the fast tuning of reference current especially for high fundamental frequency performance [21]. Furthermore, conventional expert controllers are enhanced by implementing the fuzzy interface in the case of tuning failure [22]. These expert controllers expand the stability of the responds for PI current controllers but do not improve the utilization of $V_{D C}$.

All four algorithms that have been proposed in the literature try to extend the voltage in the field weakening region by applying the optimum command for $i_{d s}^{e *}$ so that higher output torques can be achieved. However, operating drives in voltage extension regions causes increased torque ripple ([23], [24] and [25]). Consequently, despite improving PI-controller performance due to expert controllers, research in minimizing torque ripple in the field weakening region has also been conducted. For example [23] applies alterations in q-axis of stator voltage $v_{q s}^{e}$ helping to improve the dynamic performance of the current controller which in turn reduces the torque ripple. An adjusted q-axis of stator voltage $v_{q s, N e w}^{e}$ is limited to satisfy the adjustable reference voltage $K_{a d j} \frac{V_{D C}}{\sqrt{3}}$. In this way, the ordinary, $v_{q s}^{e}$, which is generated by the torque controller, is not directly used in SVM. Another technique is described in [24], where the torque control is based on the voltage angle method which improves the torque ripple. The voltage $v_{d q s}^{e}$ is obtained from the intersection of the hexagon boundary and torque equation, derived in terms of $\mathrm{d}-\mathrm{q}$ axis voltage. The placement of hexagonal voltage boundary depends on the electrical rotor position $\theta_{e}$ as voltage boundary rotates in synchronous frame. In this technique, the voltage angle $\arctan \frac{v_{q s}^{e}}{v_{d s}^{e}}$ is determined from the intersection of the voltage limitation contour and the command torque curve $T_{e}^{*}$. The reason for adding the adjusted $i_{d s}^{e}$ term to determined $\arctan \frac{v_{q S}^{e}}{v_{d s}^{e}}$ is improving the stability of the control structure which results in reduced torque ripple. Therefore, the desired voltage signals $v_{d q s, \text { New } 1}^{e}$ are produced without using the current controllers.

This paper focuses to increase the torque output at field weakening for the model-based algorithm. Reciprocal speed algorithm and voltage detection algorithm including torque ripple reducing methods require at least one extra regulator compared to model-based algorithm and lookup algorithm. Less number of regulators for developing $i_{d s}^{e *}$ makes tuning of IM drives much easier and more user friendly, especially in practical tests. Although the required number of regulators is the same in both algorithms, the lookup algorithm method requires additional experimental tests for extracting an accurate look-up table. These tests are time consuming and they require sensors with high accuracy.

So far, the control algorithm in model-based algorithm relies on the description of the inscribed voltage circle constraint that lies within the hexagonal voltage boundary. As the full hexagonal voltage boundary is never reached, the torque in the field weakening region is limited. This paper presents a calculation of $i_{d s}^{e *}$ that includes the angle of the stator voltage vector and the difference between the hexagonal voltage boundary and inscribed voltage circle. The area of the error between the hexagonal voltage boundary and the inscribed voltage circle forms a parabolic shape. Thus $i_{d s}^{e *}$ and $i_{q s}^{e *}$ include information of parabolic shape variation and it allows the measured currents to closely follow the desired currents in spite of the rotor flux lag due to the rotor time constant and error in measured currents. The closely track of desired currents means that a sufficient $\mathrm{d}$-axis voltage margin is available which allows the stability in current controllers and consequently low torque ripple. The proposed method therefore, maximizes the 
utilization of inverter input voltage resulting in higher torque and power in the field weakening region. It is worth clarifying that the work presented in this paper aimed at achieving the hexagonal voltage and not utilizing the full inverter voltage achieved by discontinuous modulation technics such as six-step control which holds the stator voltage angle in the corners of hexagonal voltage boundary ([27] ,[28] and [29]). The Appendix shows three common modulation techniques distinguishing between SVM and six-step control.

The reminder of this paper is organized as follows. Section II explains the mathematical model, voltage and current constraints and describes different operation stages of IM. Section III presents an analytical evaluation of the proposed model-based control method. Selected simulation and experimentally validated results are illustrated and discussed in Section IV. Finally, the work is concluded in Section V.

\section{MATHEMATICAL MODEL DEVELOPMENT}

\section{A. Induction Machine Model}

Fig. 1 shows the steady-state equivalent circuit model of IM, where all leakage inductances are referred to the stator side. To develop the voltage model of IM in terms of rotor flux, the stator flux $\lambda_{d q s}^{e}$ should be defined with respect to rotor flux $\lambda_{d q r}^{e}$ as shown below:

$$
\lambda_{d q s}^{e}=\sigma L_{s} I_{d q s}^{e}+\frac{L_{m} \lambda_{d q r}^{e}}{L_{r}}
$$

where $L_{s}, L_{r}$ and $\sigma$ are stator inductance, rotor inductance and leakage coefficient respectively. Now, the stator voltage model of IM can be defined as follows:

$$
\begin{aligned}
v_{d s}^{e}=r_{s} i_{d s}^{e}+\sigma L_{s} & \frac{d}{d t} i_{d s}^{e}+\frac{L_{m}}{L_{r}} \frac{d}{d t} \lambda_{d r}^{e} \\
& -\omega_{e} \frac{L_{m} \lambda_{q r}^{e}}{L_{r}}-\omega_{e} \sigma L_{s} i_{q s}^{e}
\end{aligned}
$$

$$
\begin{aligned}
v_{q s}^{e}=r_{s} i_{q s}^{e}+\sigma L_{s} & \frac{d}{d t} i_{q s}^{e}+\frac{L_{m}}{L_{r}} \frac{d}{d t} \lambda_{q r}^{e} \\
& +\omega_{e} \frac{L_{m} \lambda_{d r}^{e}}{L_{r}}+\omega_{e} \sigma L_{s} i_{d s}^{e}
\end{aligned}
$$

In (2) and (3), $r_{s}$ and $\omega_{\mathrm{e}}$ are the stator resistance and electrical rotor speed. The RFO dynamic model is produced by aligning the $\mathrm{d}$-axis of the synchronous frame to the rotor flux $\left(\lambda_{q r}^{e}=0\right)$. Then, the simplified model of IM in steady state condition can be derived as follows:

$$
\begin{aligned}
& v_{d s}^{e}=r_{s} i_{d s}^{e}-\omega_{e} \sigma L_{s} i_{q s}^{e} \\
& v_{q s}^{e}=r_{s} i_{q s}^{e}+\omega_{e} \frac{L_{m} \lambda_{d r}^{e}}{L_{r}}+\omega_{e} \sigma L_{s} i_{d s}^{e}
\end{aligned}
$$

Based on the IM model given in (4) and (5), the phasor diagram shown in Fig. 1b can be produced. As illustrated in Fig. $1 \mathrm{~b}$, the stator voltage $\overrightarrow{V_{d q}^{e}}$ is compensating the resistance voltage $r_{s} \overrightarrow{I_{s}}$, leakage inductance voltage $j \omega_{\mathrm{e}} \sigma L_{s} I_{s}$ and rotor flux voltage $\mathrm{j} \omega_{\mathrm{e}} \frac{L_{m}}{L_{r}} \overrightarrow{\lambda_{d q r}^{e}}$. Therefore, all these voltage terms need to be compensated by the stator voltage in order to increase the motor speed. However, the amplitude of $\overrightarrow{V_{d q}^{e}}$ is restricted by the inverter output voltage, which is $\frac{V_{D C}}{\sqrt{3}}$ in conventional model-based control. It is also worth noting that the power electronics inverter and the electric motor are also limited by the maximum current $I_{s, \max }$ rating. Therefore, voltage and current limitations needs to be satisfied in all speed operational regions.

\section{B. Voltage and Current Constraints}

In model-based control method, the reference flux needs to be calculated by using IM model where the stator current and stator voltage are limited as explained in Section II. A. Therefore, to address the reference flux at each rotor speed, the voltage and current constraints equations must be defined as:

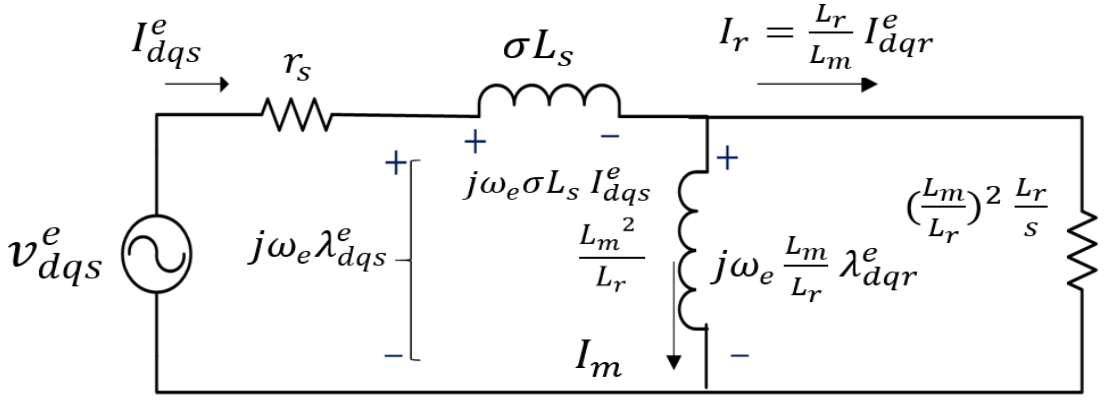

(a)

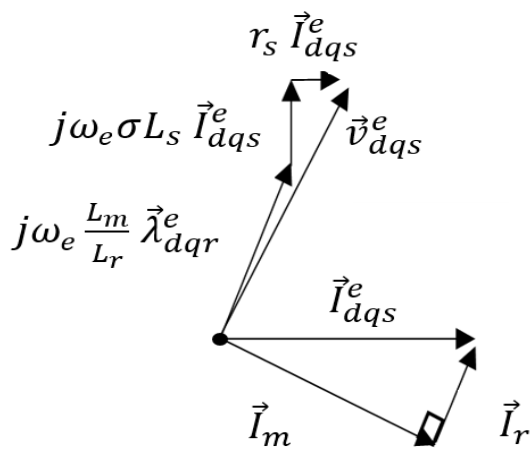

(b)

Fig. 1. Equivalent circuit of IM with all leakage inductances referred to the stator side (b) voltage vector diagram for RFO 


$$
\left\{\begin{array}{l}
\left(i_{d s}^{e}\right)^{2}+\left(i_{q s}^{e}\right)^{2} \leq\left(I_{s, \max }\right)^{2} \\
\left(v_{d s}^{e}\right)^{2}+\left(v_{q s}^{e}\right)^{2} \leq\left(V_{s, \max }\right)^{2}
\end{array}\right.
$$

As it can be seen from (6), the amplitude of stator current, which consists of $i_{d s}^{e}$ and $i_{q s}^{e}$, has to be lower than the maximum current ratings $I_{s, \max }$ of the IM and the inverter. The current constraint equation is illustrated in Fig. 2a as a circle. This current limit is satisfied as long as the stator current terms are within the circle. In model-based methods, the voltage constraint equation also needs to be defined in terms of current components. This is because the reference currents are designed based on these two constraints. Therefore, the description of voltage limitation could be expressed in terms of current with a reasonable assumption of neglecting the inductance saturation and resistance loss as shown in (4) and (5). Hence, the voltage constraint can be achieved by substituting (4) and (5) into (6), yielding (7) as follow:

$$
\frac{i_{d s}^{e}{ }^{2}}{\left(V_{\max , s}\right)^{2} /\left(\omega_{e} L_{s}\right)^{2}}+\frac{i_{q s}^{e}}{\left(V_{\max , s}\right)^{2} /\left(\omega_{e} \sigma L_{s}\right)^{2}} \leq 1
$$

This equation is presented by an ellipse graph on the Cartesian plane of $\mathrm{d}-\mathrm{q}$ axis current portrayed in Fig. 2a. The major axis of this ellipse is vertical because the value of denominator of $i_{q s}^{e}$ term in (7) is higher than of other term. This is because the existence of the leakage coefficient in $i_{q s}^{e}$ denominator has a value of less than one. Furthermore, it should

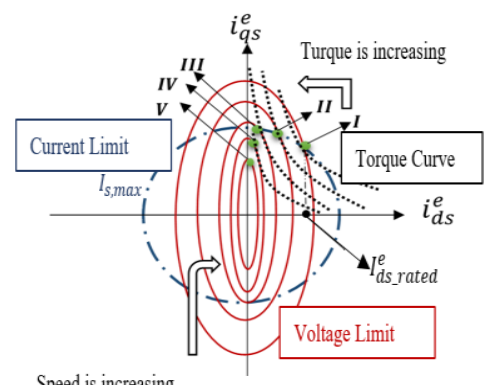

(a)

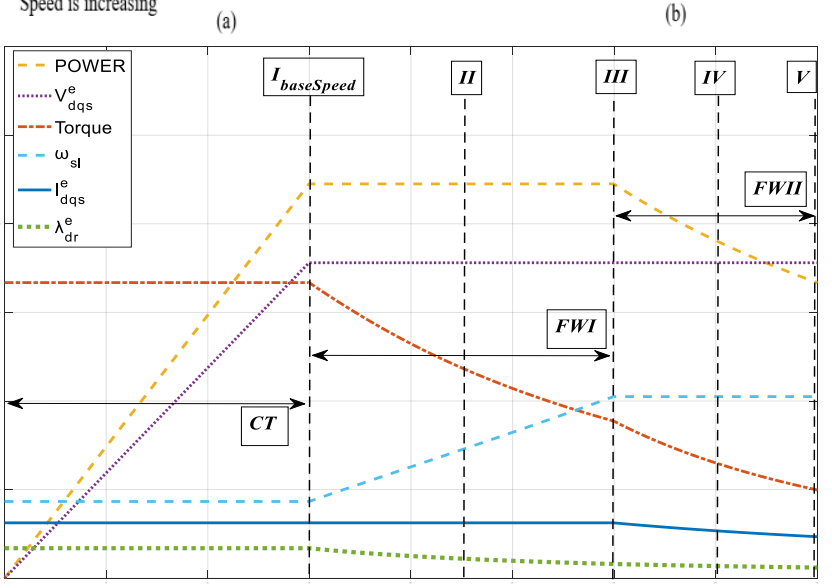

(c)

Fig. 2. (a) Current and voltage limits for IM (b) Voltage trajectory in SVM (c) Characterisation of IM in different operational regions be noted that the extra slope in the voltage ellipse along $i_{q s}^{e}$ axis needs to be considered in case of high stator resistance and low leakage coefficient $\sigma$. Likewise, the voltage limitation could be satisfied if the current terms are placed within the voltage ellipse, depicted in Fig.2 a. It should also be noted that voltage ellipse shrinks towards its centre as speed increases.

Additionally, the maximum available voltage in SVM $V_{s, \max }$ plays an important role to satisfy the voltage constraint as it can be seen from (7). This inverter voltage is utilised by the stator voltage, $\overrightarrow{V_{d q}^{e}}$ of the IM to compensate motor voltage terms depicted in Fig. 1a. Figure 3 shows that $\overrightarrow{V_{d q}^{e}}$ is compensating the two main voltage terms of the motor, $j \omega_{\mathrm{e}} \frac{L_{m}}{L_{r}} \overrightarrow{\lambda_{d q r}^{e}}$ and $j \omega_{\mathrm{e}} \sigma L_{s} I_{s}$ in the constant torque region. The amplitudes of $j \omega_{\mathrm{e}} \sigma L_{s} I_{s}$ and $j \omega_{\mathrm{e}} \frac{L_{m}}{L_{r}} \overrightarrow{\lambda_{d q r}^{e}}$ are increasing with the speed, which requires higher voltage to be extracted from the inverter. As shown in Fig.3 a, the rotor flux voltage $j \omega_{\mathrm{e}} \frac{L_{m}}{L_{r}} \overrightarrow{\lambda_{d q r}^{e}}$ is the dominant term of the stator voltage at the starting point of the first stage of field weakening (FWI). Therefore, to operate in the first stage of field weakening, reducing the magnetizing current $I_{m}$ (i.e. hence $\overrightarrow{\lambda_{d q r}^{e}}$ ) is considered as an effective way to satisfy the voltage constraint. On the other hand, further reduction of $I_{m}$ in FWI, results in voltage drop across $\omega_{\mathrm{e}} \frac{L_{m}}{L_{r}} \overrightarrow{\lambda_{d q r}^{e}}$. Consequently, this makes $\omega_{\mathrm{e}} \sigma L_{s} I_{S}$ the dominating element of the absorbed voltage in second stage of the field weakening (FWII) as shown in Fig. 3b. To satisfy both voltage and current constraints in motor control applications, the different operational regions need to be considered in designing the reference currents as explained in the next Section.

C. Constant Torque (CT), First Stage of Field Weakening (FWI) and Second Stage of Field Weakening Regions (FWII)

Due to the current and voltage constraints, operation of IM is split into three different speed regions (Fig. 2c). As shown at Point I in Fig. 2a, c, the maximum torque is generated based on the rated flux level and the inverter/machine current limitation in the low speed region (below base speed) [26]. The region below the base speed is called Constant Torque (CT). So, the maximum available $i_{q s}^{e}$ is calculated as follows:

$$
\left\{\begin{array}{l}
i_{d s}^{e *}=i_{d s-\text { rated }}^{e} \\
i_{q s}^{e *}=\sqrt{\left(I_{s, \text { max }}\right)^{2}-\left(i_{d s-\text { rated }}^{e}\right)^{2}}
\end{array}\right.
$$

The calculated base speed has to be adjusted based on the flux level at the rated condition which is varied according to rated current. In general, a high current rating, which produces large flux value, causes the lower base speed. The base speed is the starting point of FWI where the maximum power is delivered to the machine by reducing the flux level (Fig. 2c). 


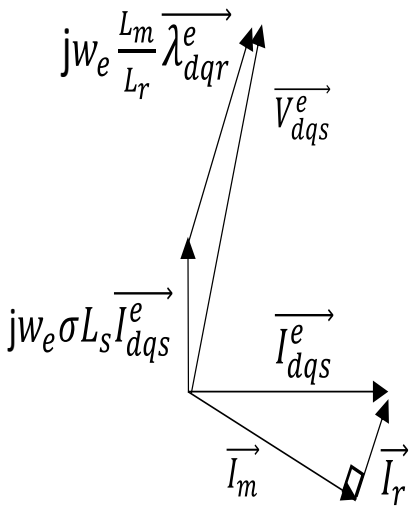

(a)

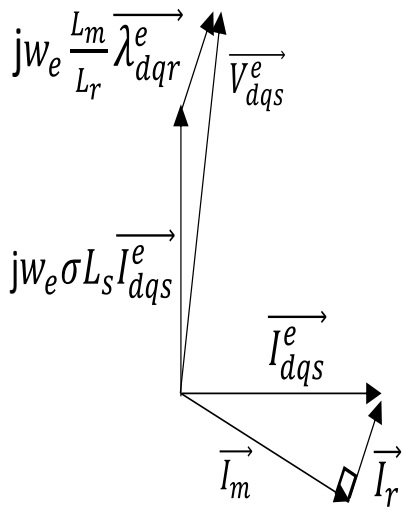

(b)
Fig. 3. Phasor diagram for stator voltage in (a) First stage of field weakening (b) Second stage of field weakening

This flux reduction maintains the back electromagnetic force component $\left(\omega_{\mathrm{e}} \frac{L_{m} \lambda_{d r}^{e}}{L_{r}}\right)$ at nearly constant level. As shown in Fig. 2a, c, the rotor flux is reduced from point I to III by decreasing $i_{d s}^{e}$. In model-based voltage control, the reference $\mathrm{d}$-axis and q-axis current signals are calculated by using (6), (7), which can be expressed as:

$$
\left\{\begin{array}{l}
i_{q s}^{e *}=\frac{4 T_{e}^{*} L_{r}}{3 P L_{m}^{2} i_{d s}^{e}} \\
i_{d s}^{e *}=\sqrt{\frac{\left(V_{s, \max }\right)^{2}}{2\left(\omega_{\mathrm{e}} L_{s}\right)^{2}}+\frac{1}{2} \sqrt{\left(\frac{\left(V_{s, \max }\right)^{2}}{\left(\omega_{\mathrm{e}} L_{s}\right)^{2}}\right)^{2}-4\left(\frac{4 \sigma T_{e}^{*} L_{r}}{\omega_{\mathrm{e}} 3 P L_{m}^{2}}\right)^{2}}}
\end{array}\right.
$$

In case the maximum torque is required at any speed, then the maximum q-axis current is used and therefore, (9) becomes:

$$
\left\{\begin{array}{l}
i_{q s}^{e *}=\sqrt{\left(I_{s, \text { max }}\right)^{2}-\left(i_{d s}^{e *}\right)^{2}} \\
i_{d s}^{e *}=\sqrt{\frac{\left(V_{s, \text { max }}\right)^{2}-\left(\omega_{\mathrm{e}} \sigma L_{s}\right)^{2}\left(I_{s, \text { max }}\right)^{2}}{\left(\omega_{\mathrm{e}} L_{s}\right)^{2}-\left(\omega_{\mathrm{e}} \sigma L_{s}\right)^{2}}}
\end{array}\right.
$$

As the speed is increasing in region FWI, the slip speed becomes close to its maximum value (Fig. 2c). This is because the available applied q-axis current reaches the limit and slip speed cannot be further increased. Hence, this is the point where FWII region begins. The maximum torque in this high-speed stage is achieved by keeping the angle between stator and rotor flux at $45^{\circ}$. In this case, the torque-producing-current is reduced as shown in Point III to V in Fig. 2a, which leads to a reduction in output power of IM. The current reduction continues until the voltage vector with an amplitude of $V_{s, \max }$ is placed at $90^{\circ} \mp 45^{\circ}$ in synchronous frame. This condition can be achieved by:

$$
\begin{aligned}
& i_{d s}^{e *}=\sqrt{\frac{\left(V_{s, \max }\right)^{2}}{2\left(\omega_{e} L_{s}\right)^{2}}} \\
& i_{q s}^{e *}=\sqrt{\frac{\left(V_{s, \max )^{2}}\right.}{2\left(\omega_{e} \sigma L_{s}\right)^{2}}} \\
& w_{s l_{-} \max }=\frac{i_{q s}^{e *}}{\tau_{r} i_{d s}^{e *}}=\frac{1}{\tau_{r} \sigma}
\end{aligned}
$$

So in this speed region, the value of torque-producingcurrent can be presented as proportional of flux-producingcurrent $\left(i_{q s}^{e *}=\frac{i_{d s}^{e *}}{\sigma}\right)$. In conventional model based control, the calculated $i_{d s}^{e *}$ in (8) to (12) is limited by the inscribed voltage circle within the hexagonal voltage boundary (Fig. 2b).

\section{THE PROPOSED METHOD}

The proposed algorithm for field weakening regions is portrayed in Fig. 4, where the output torque of the IM is increased by having higher utilization of $V_{D C}$ in SVM.

This is happened by substituting the equation of each side of the hexagon voltage limitation (14) to (19) for corresponding angle of stator voltage vector $\theta_{v}$ into (9) to (12). So, in this case, the stator voltage vector reaches the hexagon boundary. The equations for each side of hexagon in terms of $\mathrm{d}-\mathrm{q}$ axis of voltage components are derived based on $\theta_{v}$ as follows:

$$
\begin{aligned}
& 0 \leq \theta_{v}<\frac{\pi}{3} \\
& V_{s, \max }{ }^{2}=\left(\frac{2}{3} V_{D C}\left(1-\frac{\frac{\sqrt{3}}{3} \tan \theta_{v}}{\frac{\sqrt{3}}{3} \tan \theta_{v}+1}\right)\right)^{2} \\
& +\left(\frac{2}{3} V_{D C}\left(\frac{\tan \theta_{v}}{\frac{\sqrt{3}}{3} \tan \theta_{v}+1}\right)\right)^{2} \\
& \frac{\pi}{3} \leq \theta_{v}<\frac{2 \pi}{3} \\
& V_{s, \max }{ }^{2}=\left(\frac{2}{3} V_{D C}\left(\frac{\sqrt{3}}{2} \tan \left(\frac{\pi}{2}-\theta_{v}\right)\right)\right)^{2}+\left(\frac{2}{3} V_{D C} \frac{\sqrt{3}}{2}\right)^{2} \\
& \frac{2 \pi}{3} \leq \theta_{v}<\pi \\
& V_{s, \text { max }}{ }^{2}=\left(\frac{2}{3} V_{D C}\left(\frac{\frac{\sqrt{3}}{3} \tan \left(\pi-\theta_{v}\right)}{\frac{\sqrt{3}}{3} \tan \left(\pi-\theta_{v}\right)+1}-1\right)\right)^{2} \\
& +\left(\frac{2}{3} V_{D C}\left(\frac{\tan \left(\pi-\theta_{v}\right)}{\frac{\sqrt{3}}{3} \tan \left(\pi-\theta_{v}\right)+1}\right)\right)^{2} \\
& \pi \leq \theta_{v}<\frac{4 \pi}{3} \\
& V_{s, \max }{ }^{2}=\left(\frac{2}{3} V_{D C}\left(-1-\frac{\frac{\sqrt{3}}{3}\left(-\tan \left(\theta_{v}-\pi\right)\right)}{\frac{\sqrt{3}}{3} \tan \left(\theta_{v}-\pi\right)+1}\right)\right)^{2} \\
& +\left(\frac{2}{3} V_{D C}\left(\frac{-\tan \theta_{v}}{\frac{\sqrt{3}}{3} \tan \left(\theta_{v}-\pi\right)+1}\right)\right)^{2}
\end{aligned}
$$




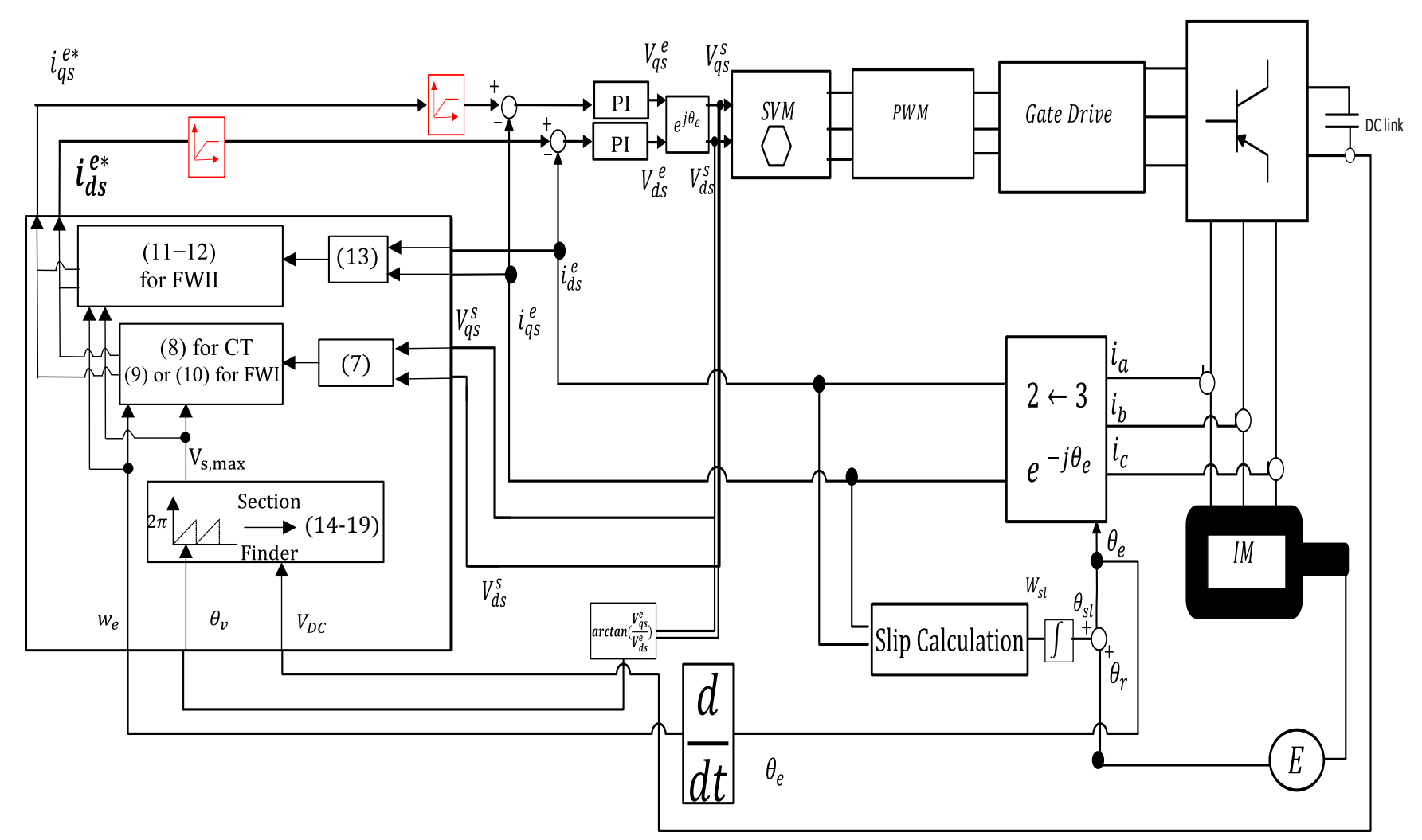

(a)

$$
\begin{aligned}
& \frac{4 \pi}{3} \leq \theta_{v}<\frac{5 \pi}{3} V_{s, \max }^{2} \\
& =\left(\frac{2}{3} V_{D C}\left(\frac{\sqrt{3}}{2} \tan \left(\frac{3 \pi}{2}-\theta_{v}\right)\right)\right)^{2} \\
& +\left(\frac{2}{3} V_{D C} \frac{\sqrt{3}}{2}\right)^{2} \\
& \frac{5 \pi}{3} \leq \theta_{v}<2 \pi V_{s, \max }^{2} \\
& =\left(\frac{2}{3} V_{D C}\left(+1-\frac{\frac{\sqrt{3}}{3}\left(-\tan \left(2 \pi-\theta_{v}\right)\right)}{\frac{\sqrt{3}}{3} \tan \left(2 \pi-\theta_{v}\right)+1}\right)\right)^{2} \\
& +\left(\frac{2}{3} V_{D C}\left(\frac{-\tan \theta_{v}}{\frac{\sqrt{3}}{3} \tan \left(2 \pi-\theta_{v}\right)+1}\right)\right)^{2}
\end{aligned}
$$

As shown in Fig. 4a, b, $V_{d q s}^{e}$ and $i_{d q s}^{e}$ are used in (7) and (13) to detect the operation regions that facilitate smooth and automatic transition of the proposed algorithm between CTFWI and between FWI-FWII.

To evaluate the performance of the proposed control method, the maximum calculated $i_{q S}^{e *}$ in (10) is directly applied to the machine instead of using its value from the torque controller. As shown in Fig. 5a, the maximum voltage magnitude, which is moving along the hexagon trajectory, is changing according to $\theta_{v}$ in any electrical cycle. The proposed model-based method exploits more DC-link voltage range to increase the output torque and power of the IM.

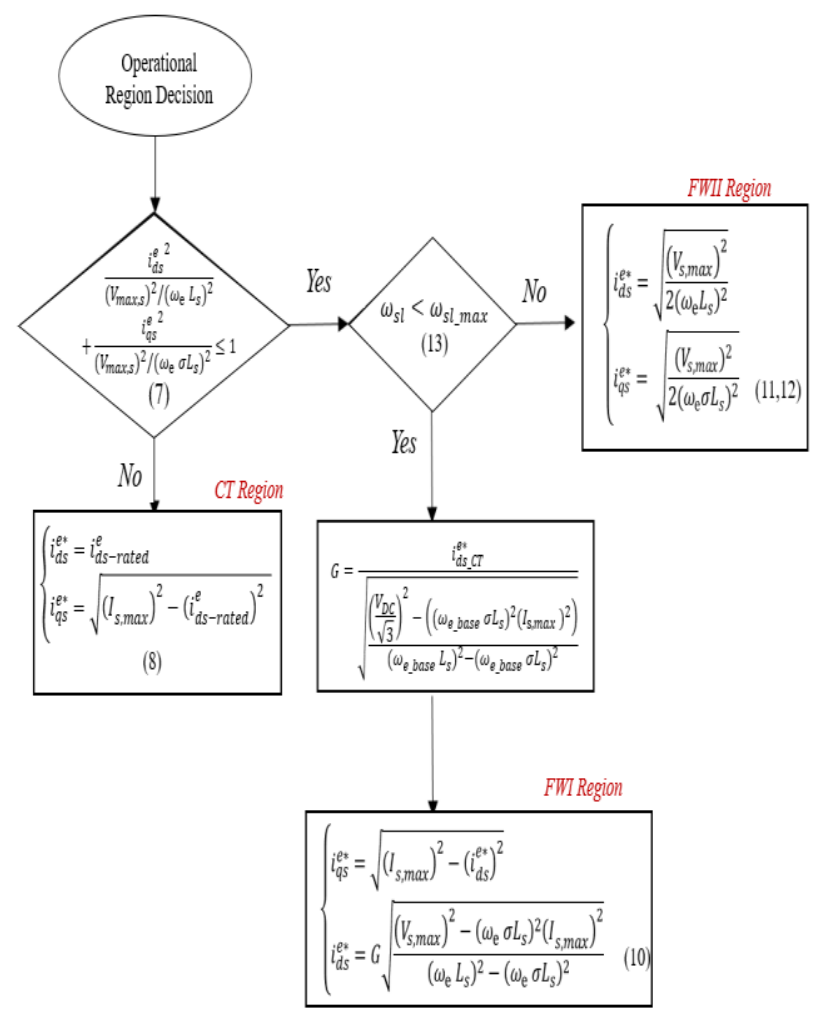

(b)

Fig. 4. Proposed model-based controller (a) Block diagram of IM drive (b) Algorithm flowchart 
As shown in Fig. 6, the area of voltage constraint is extended in the proposed method. Comparing points A and B in Fig. 6 reveals that the voltage extension results in the IM being able to operate at a higher speed for the same $V_{D C}$. This is because more voltage is available to compensate for the back EMF at higher speed. This is the reason that the voltage limitation of point $\mathrm{C}$ (placed in proposed voltage trajectory) at $1,700 \mathrm{rpm}$ is close to point B (placed in conventional voltage trajectory) at $1,500 \mathrm{rpm}$. Similarly, by a closer look at points $\mathrm{C}$ and D on Fig. 6 , one can see that higher voltage at point $\mathrm{C}$ results in a higher torque as demonstrated in Fig. 2a.

Furthermore, the maximum torque possible from the proposed method which satisfies the voltage and current constraints are shown in Fig. 7 for different speeds. It is worth mentioning that these maximum torque values at different speed operation are achieved in experimental test. In addition, the calculated optimum value of d-axis current reduces the required number of regulators in this method, which simplifies the control system. As depicted in Fig. 4, the reference d-axis current is produced based on mathematical equations without applying any regulators such as one used in reciprocal algorithm, voltage detection algorithm and lookup table algorithm. In those Methods, the reference d-axis current is produced based on a flux regulator, voltage regulator and lookup table, respectively. In practice, tuning these regulators is usually based on the trial and error, which requires a lot of efforts and time and more importantly, optimum performance is not guaranteed.

Using the proposed algorithm causes that the closed-loop controlled system retains its stability even in maximum voltage utilisation condition. This is a result of the parabolic waveform changes in d-axis reference current which apply the minimum current to satisfy the voltage boundary (As demonstrated in Fig. 5). This allows the measured current to closely track the desired current in spite of the lag in rotor flux and error in measured motor currents. This results in sufficient $\mathrm{d}$-axis voltage margin to allow good dynamic performance for current controller with a consequent reduction in torque ripple.

As shown in (2), if there is insufficient d-axis of voltage, which happens in case of high error in d-axis current controller, then the q-axis current will be decreased. Under this condition

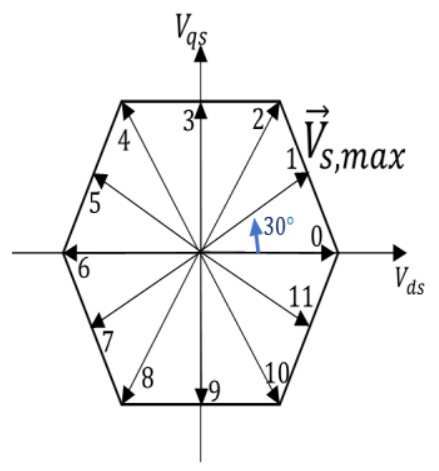

(a)

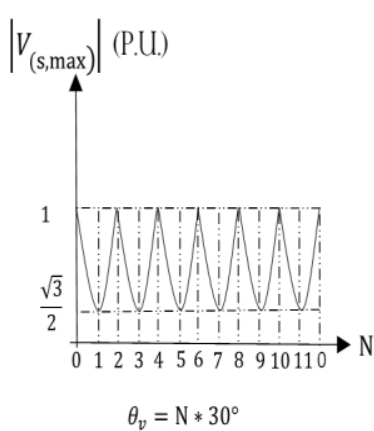

(b)
Fig. 5. (a) Trajectory of maximum available voltage vector (b) Amplitude of the maximum voltage vector

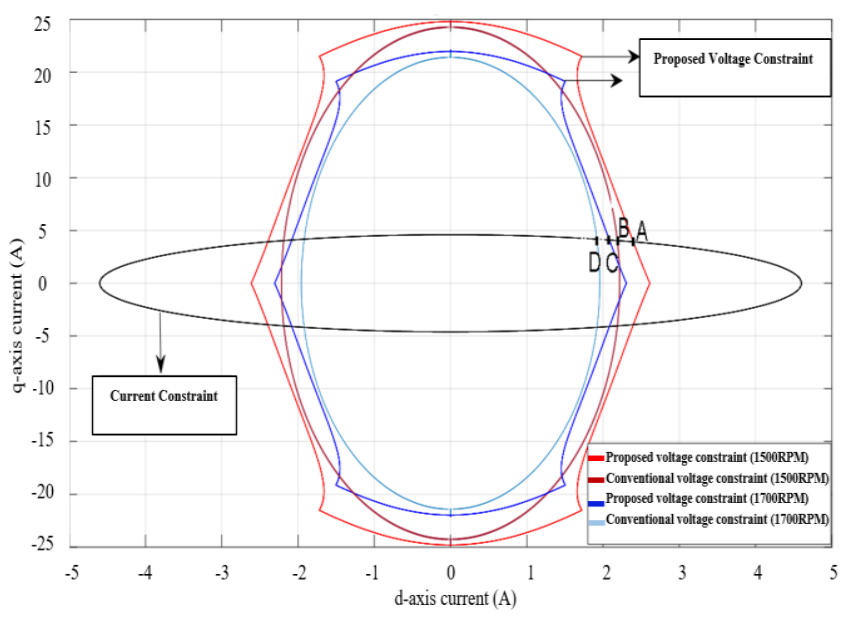

Fig. 6. Comparison of voltage constraint in proposed and conventional model-based method

the q-axis current fails to follow its reference current resulting in increased torque ripple. The automatic transition from the CT region to FWI and from FWI to FW2 can also be achieved due to the algorithm recognizing the transition points using (7) and (13). The automatic transition also provides starting points for the $i_{d s}^{e *}$ in FWI region to be matched with the reference d-axis current in CT region. This is due to the use of a gain which is multiplied by the d-axis current in (9) or (10) to ensure the correct starting value for $i_{d s}^{e *}$ when transferring between regions (as demonstrated in Fig. 4b). Moreover, it should also be noted that the Gain $G$ is only calculated in the first PWM cycle at the start of field weakening. This ensures that the minimum value of the parabolic d-axis current will be equal to the reference value of d-axis current in constant torque region, $i_{d s-C T}^{e *}$, as illustrated in Fig.9. This results in a very smooth torque transient without the need to calculate the base speed.

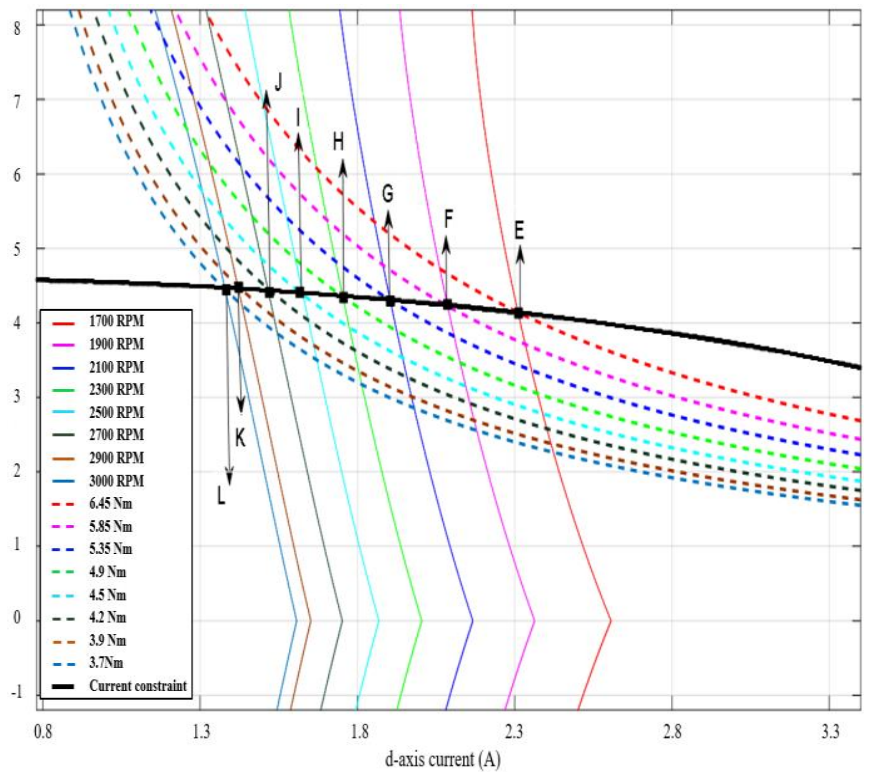

Fig. 7. Maximum torque produced by the proposed method at different speeds for the IM characterized in Table I (black solid line: current constraint; other solid lines: voltage constraint at different speeds; dashed lines: torque) 
The parameters of the tested IM are presented in Table.1. The proposed control approach is implemented using a dualcore TMS320F28377D microcontroller. CPU1 of the controller is used to realize the control model presented in Fig 4, whereas the d-q axis current controllers and SVM are implemented on CPU1.CLA. The execution time of main interrupt service routine running in CPU1 is $11.18 \mathrm{us}$ for $20 \mathrm{kHz}$ switching frequency. The current controllers and SVM running on CPU1.CLA execute in 5.32us. The experimental setup is based on a test IM coupled with a dynamometer based on permanent magnet machine as depicted in Fig.8a. Sensing is provided by three CAS 15-NP current sensors, an AD215 ISO_AMP voltage sensor and a Gurley 2048-line optical encoder. To test the IM with the proposed torque-based controller, the speed is adjusted with the dynamometer. The corresponding reference d-axis currents is calculated based on operating speed to increase the utilisation of $V_{D C}$ and therefore increases the output torque. As the maximum speed of the load machine is restricted to 3,000 rpm, the field weakening region of test IM is started at lower base speed by applying $350 \mathrm{~V}$ inverter input voltage instead of $700 \mathrm{~V}$. Thus, tests were conducted at $1.1 \mathrm{~kW}$ instead of $2.2 \mathrm{~kW}$ which is the rated power of the test motor.

Table 1. Specification of Induction machine $(1.1 \mathrm{~kW})$

\begin{tabular}{|c|c|c|c|c|}
\hline$r_{s}$ & $r_{r}$ & $V_{D C}$ & $\begin{array}{c}\text { Current } \\
\text { (Peak) }\end{array}$ & $\begin{array}{c}\text { Poles } \\
\text { Number }\end{array}$ \\
\hline $2.21 \Omega$ & $2.5067 \Omega$ & $350 \mathrm{~V}$ & $4.6 \mathrm{~A}$ & 4 \\
\hline$L_{s}$ & $L_{m}$ & $L_{r}$ & $\begin{array}{c}\text { Full-load } \\
\text { speed }\end{array}$ \\
\hline $0.2842 \mathrm{H}$ & $0.2709 \mathrm{H}$ & $0.2842 \mathrm{H}$ & $\begin{array}{c}1,500 \\
\text { RPM }\end{array}$ & 3,000 \\
\hline
\end{tabular}

(a)

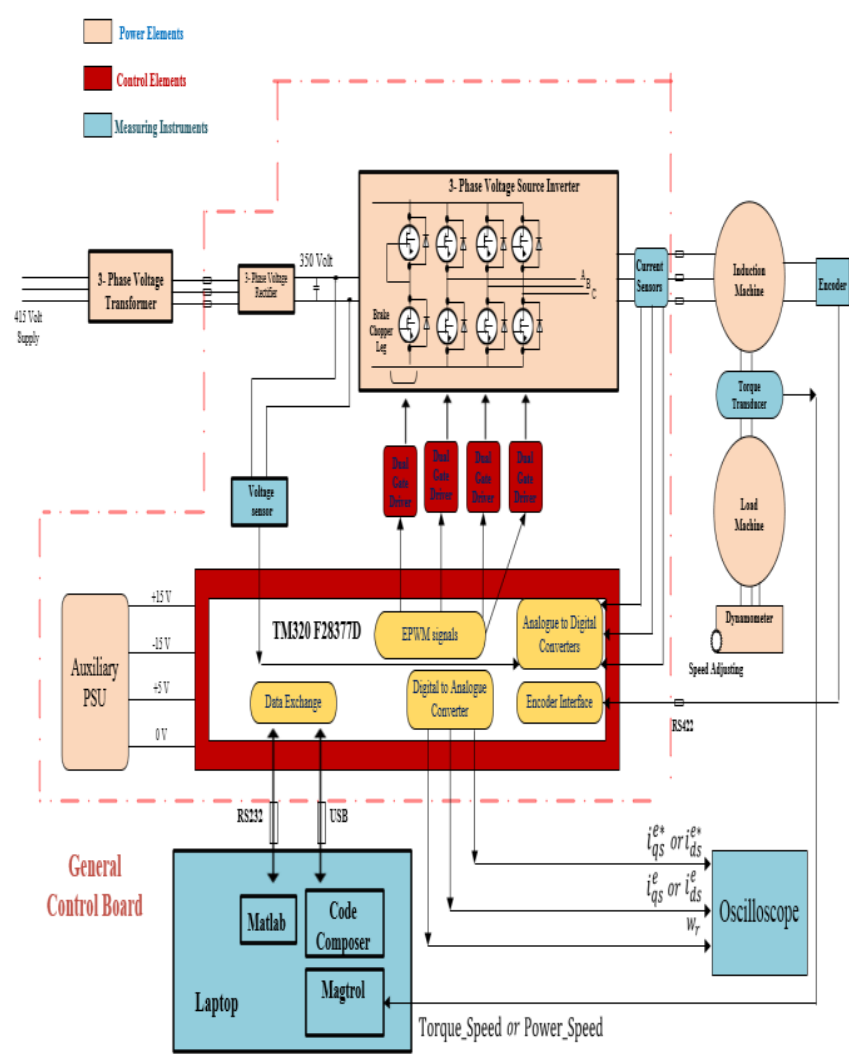

(b)

Fig. 8. (a) Experimental setup (b) Schematic Diagram of Experimental setup

Fig. 9 shows the simulation results of proposed controller from CT region to FW region. The theoretical analysis in Part $\mathrm{C}$ of Section II and the graph shown in Fig. 2 are confirmed by decreasing the d-axis current in Fig. 9a. It shows that command for the flux-producing current $i_{d s}^{e *}$ has a sequence of parabolic shape that varies with $\theta_{v}$ and it is closely followed by measured the d-current. This is because the parabolic variation of $i_{d s}^{e *}$ in proposed method ensures that the produced back EMF is always compensated by available inverter voltage. This is achieved by limiting the motor rotor flux, which is the filtered version of daxis current, in an acceptable boundary range corresponding to parabolic variation of $i_{d s}^{e *}$. As mentioned before, the rotor flux shapes the back EMF in q-axis voltage. However, the d-axis component of the stator voltage vector is shaped from the parabolic d-q axis current which is not filtered. The d-axis voltage, which is unfiltered variable shaped by d-q axis current, produces the parabolic variation of stator voltage and filtered flux producing current in q-axis voltage changes the average of stator voltage magnitude. Therefore, the stator voltage magnitude is changed parabolically to satisfy the hexagonal voltage boundary. As a result of extracting enough DC-link voltage, the motor current can still follow the $\mathrm{d}$ and $\mathrm{q}$ current references without any failure in current controllers even in high speed acceleration rate. As can be realised from Fig. 9a, the acceleration from 2,400RPM to 2420 RPM corresponds to 8.5 parabolic variations. This means that the motor accelerates 20RPM in 0.017 second as shaft rotates $8.5 / 12$ cycle. 
Therefore, the proposed method is tested in fast speed acceleration rate where an acceleration of 1,000RPM happens in 0.85 second.

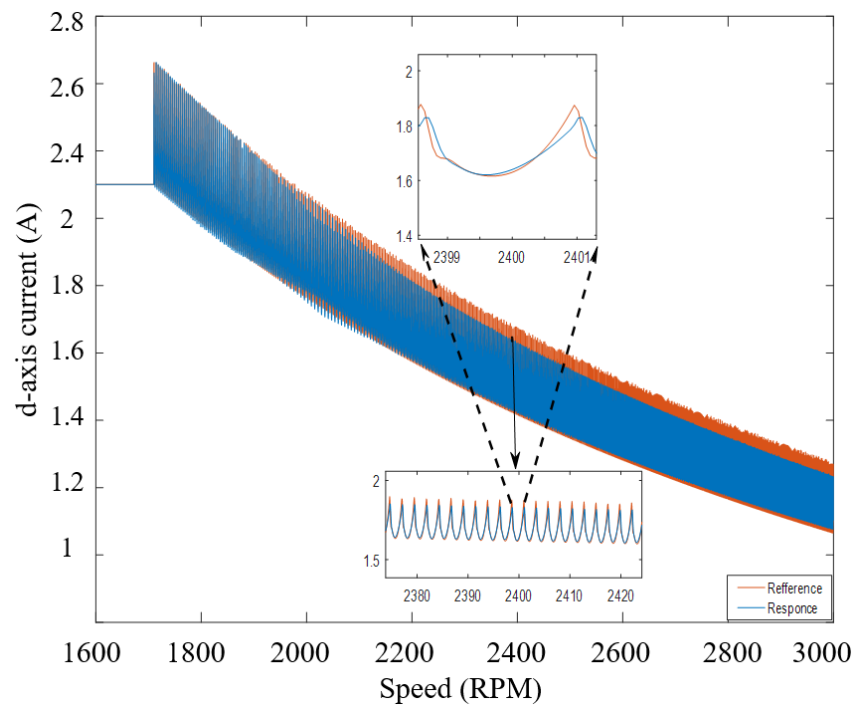

(a)

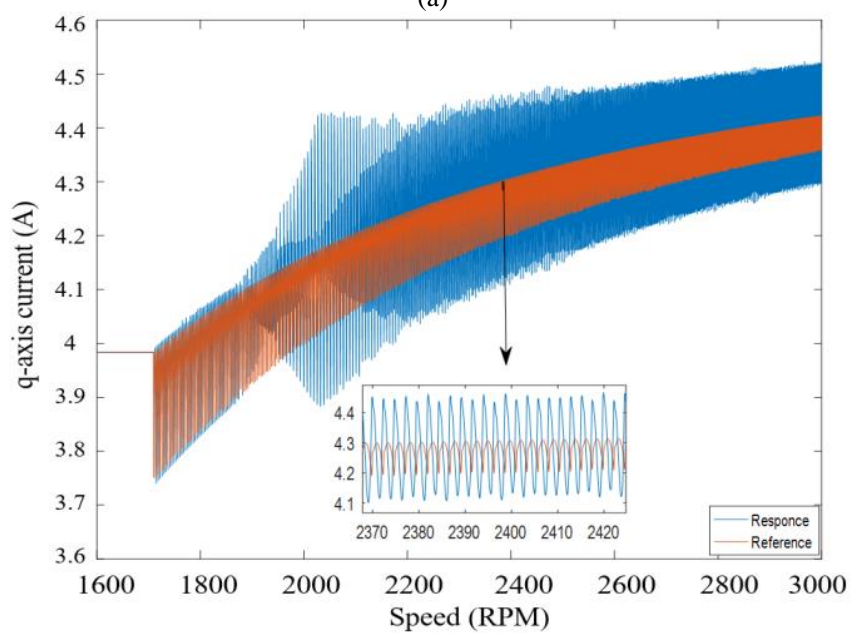

(b)

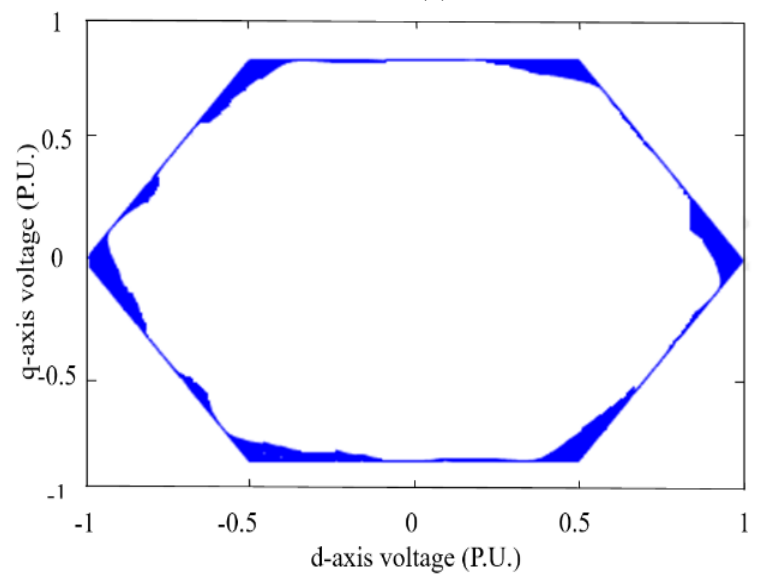

(c)

Fig. 9. Simulation results. (a) d-axis current. (b) q-axis current (c) voltage trajectory (P.U.) in rotor speed of 2,400rpm.
It should be noted that tracking of reference currents with fast parabolic variation rate can be explained based on defined bandwidth of the closed loop controller [30]. The proposed method in this manuscript was tested on IM running up to

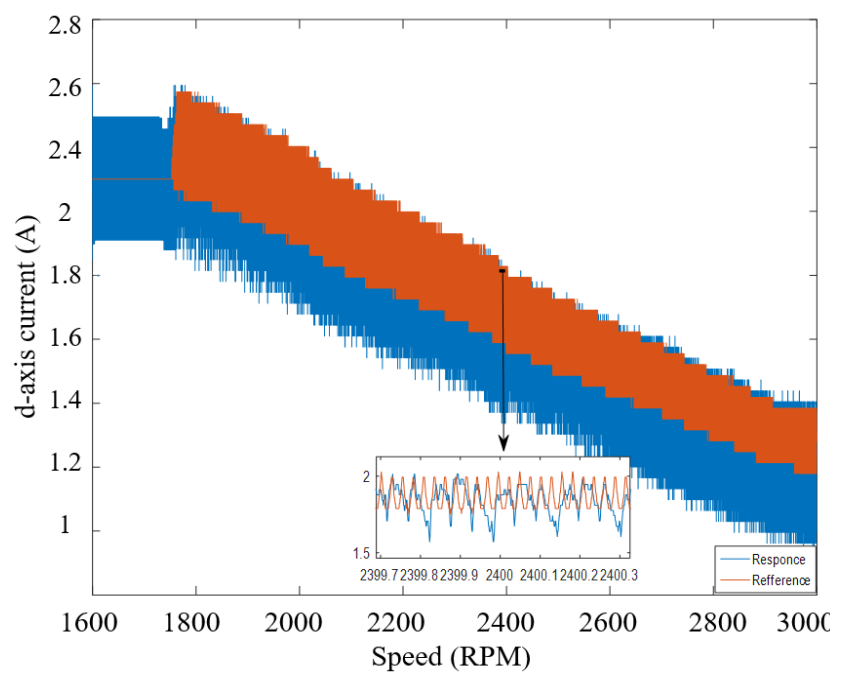

(a)

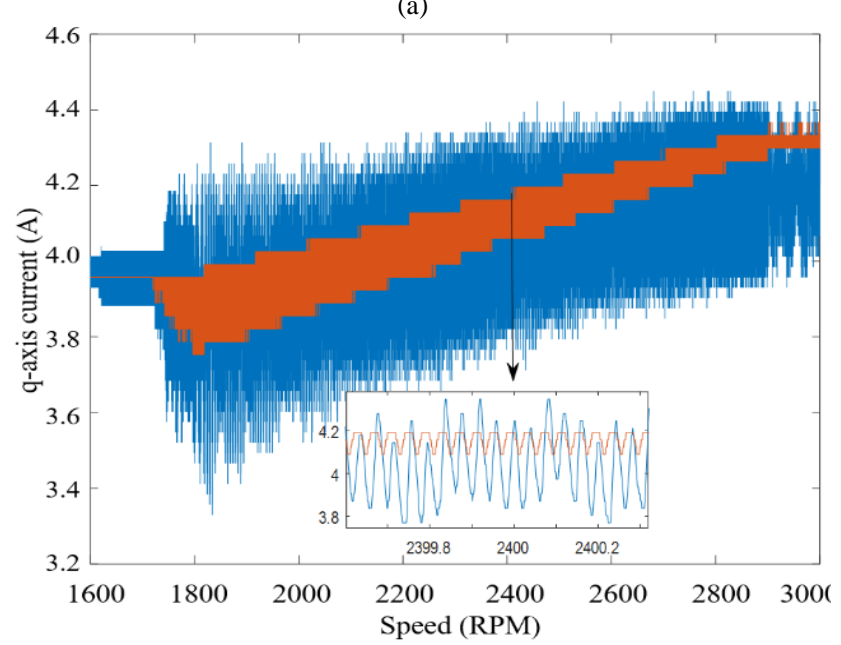

(b)

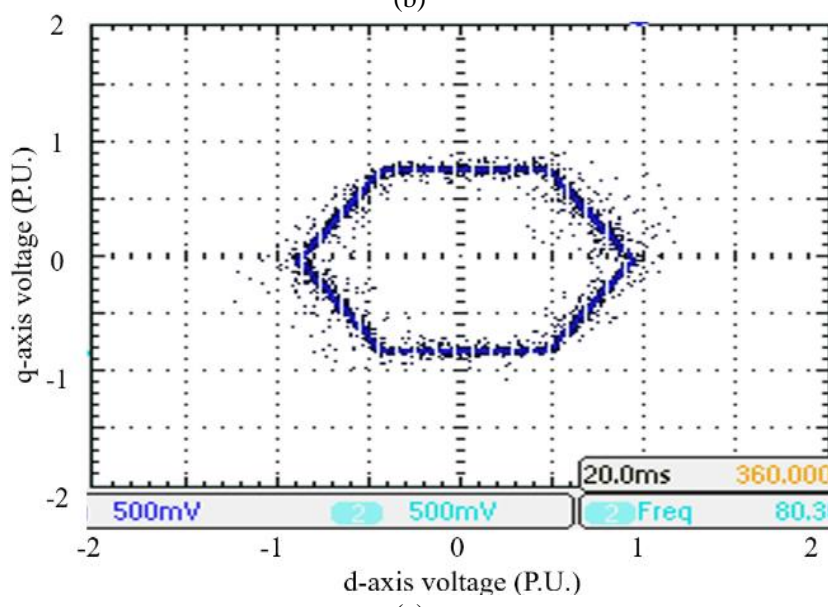

(c)

Fig. 10. Experimental results. (a) d-axis current. (b) q-axis current (c) voltage trajectory (P.U.) in rotor speed of 2,400rpm. 
$3,000 \mathrm{RPM}$. This speed corresponds to $102 \mathrm{~Hz}$ (electrical plus slip frequencies). The proposed method defines six parabolic variations in $\mathrm{d}-\mathrm{q}$ axis of the reference currents per electrical cycle. Thus, the PI controller used with this method requires a bandwidth of $612 \mathrm{~Hz}$.

The increment of q-axis current in Fig. $9 b$ is the result of satisfying the current constraint explained in (11) and confirmed in Fig. 11a. As shown in Fig. 9c, the voltage vector trajectory is contained within the hexagon boundary corresponding to that explained in Fig. 2b. In addition, Fig. 11b, shows the d-q axis of voltages at 2,400 rpm which guarantees extracting the hexagonal voltage in terms of $\mathrm{d}-\mathrm{q}$ axis voltage components as derived in (14) to (19). The blue trace in Fig. $11 \mathrm{~b}$ illustrates the $\mathrm{q}$-axis voltage which continuously moves from $-\frac{\sqrt{3}}{2}$ to $\frac{\sqrt{3}}{2}$ P.U. depending on the angle of stator voltage vector. The maximum of q-axis voltage happens when stator voltage vector moves from 2 to 4 in Fig. 5a. In this region, the $\mathrm{d}$-axis voltage, which is shown by red trace in Fig. 11, continuously moves from 0.5 to,-0.5 P.U. The voltage components in Fig. 11 clearly demonstrate that the stator voltage vector is rotating around voltage boundary and it is not

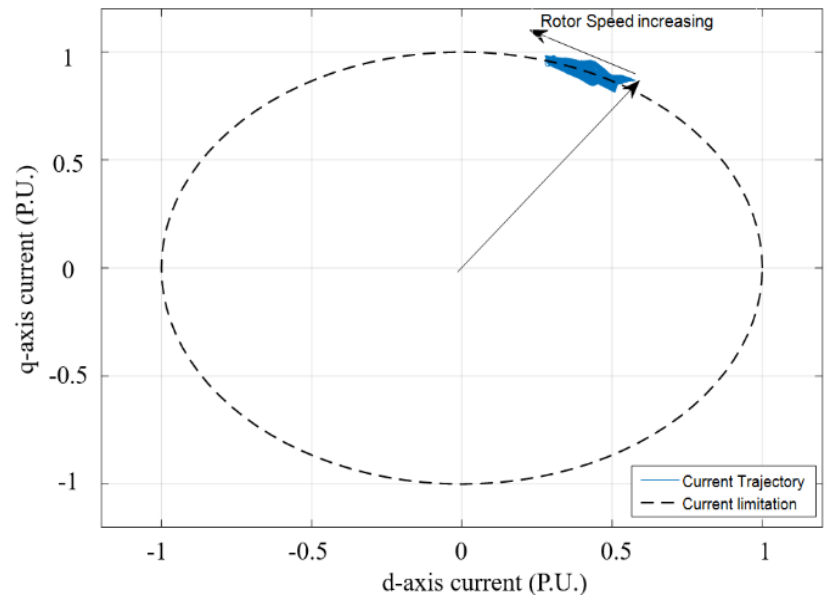

(a)

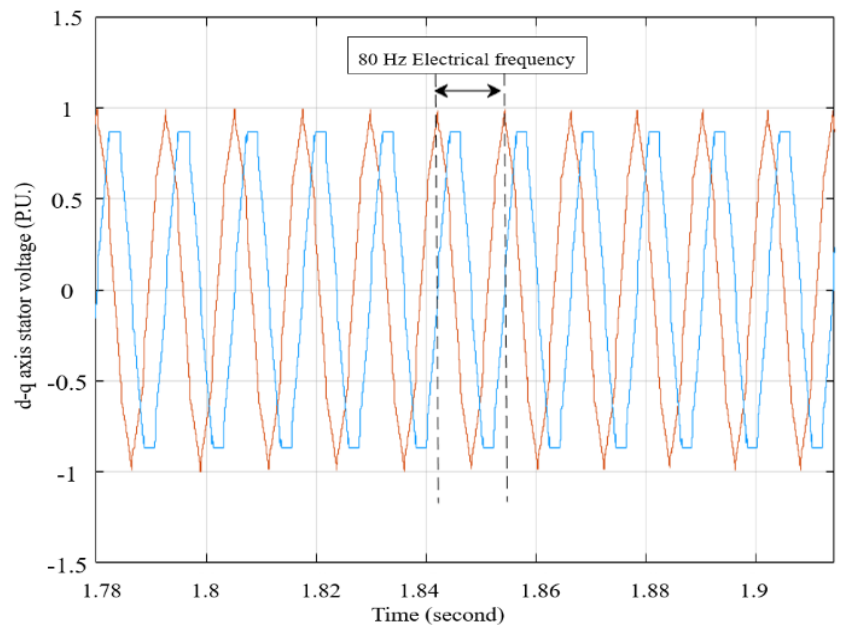

(b)

Fig. 11. Simulation results. (a) Current trajectory from standstill to 3,000 rpm. (b) d-q-axis of voltage (P.U.) in stationary frame at 2,400 rpm hold at multiplication of sixty degree, which happens in six-step control. It is worth mentioning that the $\mathrm{d}$-axis and q-axis voltages only are placed in $1, \pm 0.5$ P.U. and $0, \pm \frac{\sqrt{3}}{2}$ P.U. respectively in six step control.

As shown in Fig. 9a, the automatic and smooth transition from $\mathrm{CT}$ to $\mathrm{FW}$ is achieved in proposed algorithm as the starting point of $i_{d s}^{e *}$ in FWI is matched with the value in CT region. The experimental results in Fig. 10 and 12 show good agreement with the corresponding simulation results. As shown in Fig. 8b, the speed and reference and measured d-q axis currents are captured by oscilloscope via Digital to analogue converters (DACs). Since there are only three DACs available in the microcontroller used in the experiment, separate tests have been conducted, where $i_{d s}^{e *}, i_{d s}^{e}$ and speed, are shown in Fig. 10a, while $i_{q s}^{e *}, i_{q S}^{e}$ and speed, are illustrated in Fig. 10b have been captured. It is worth mentioning that the small difference between measured $i_{d s}^{e}$ and $i_{q s}^{e}$ in Matlab simulation and experimental results is due to the existing error in current sensors and the offset in analogue to digital convert (ADC). Also, the noise sensitivity of the DAC signals, which are in the

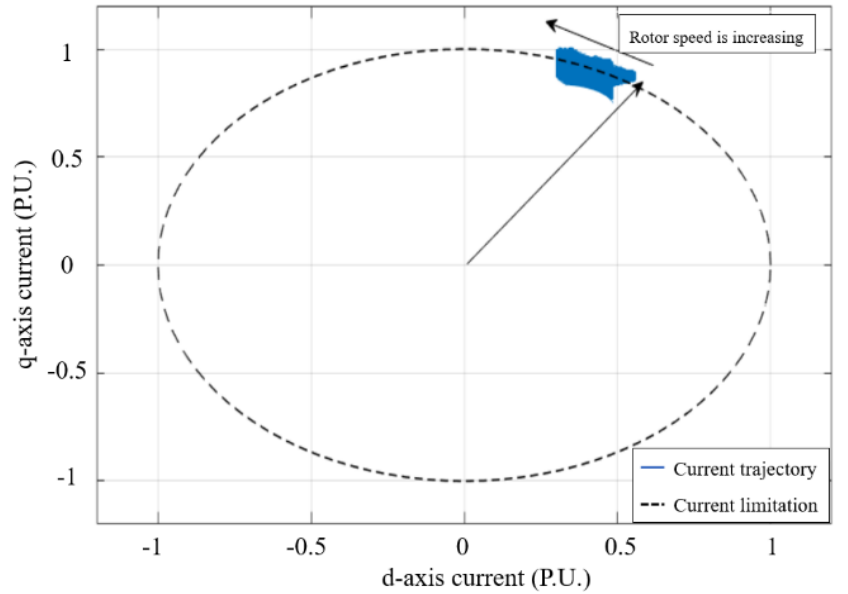

(a)

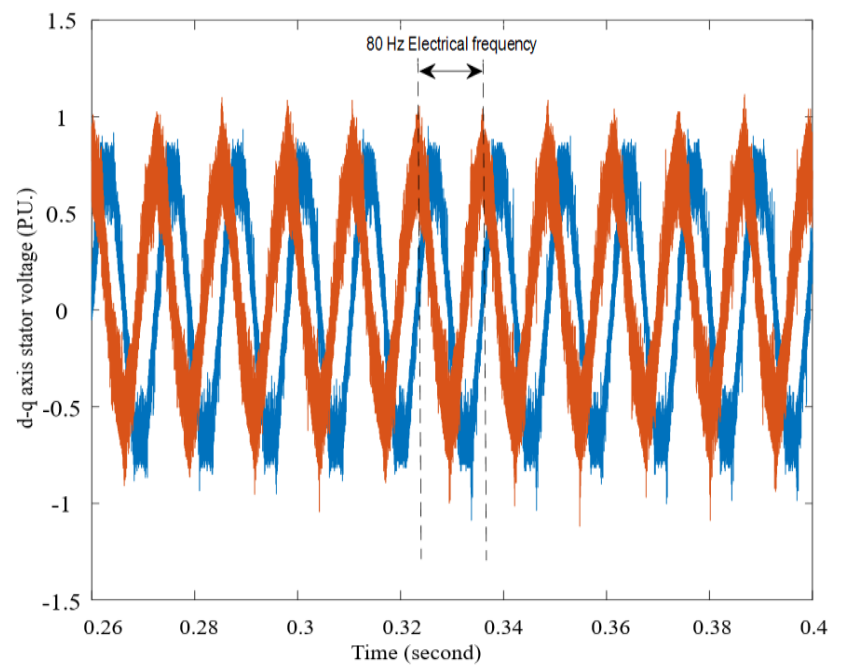

(b)

Fig. 12. Experimental results. (a) Current trajectory from standstill to 3,000 rpm. (b) d-q-axis of voltage ((P.U.) in stationary frame at 2,400 rpm 
low voltage range of 0 to $3 \mathrm{~V}$, causes the ripples in measured current signals even in $\mathrm{CT}$ region. It should be noted that the inductance saturation for high power IMs needs to be considered as another factor for stator current oscillations in model-based control algorithm. Therefore, the online estimation of motor parameters is required [31].

In Fig. 13, the degradation of the dynamic performance of PI controllers and $i_{q s}^{e}$ ripples is illustrated based on a situation which $i_{d s}^{e *}$ and $i_{q s}^{e *}$ is kept constant at the maximum value instead of parabolic variation. This causes to have higher average value of back-emf voltage comparing with proposed method where the reference currents have parabolic variation in order to keep satisfying the voltage boundary. As shown in Fig. 13, the current controllers are struggling to keep the motor currents in track when the stator voltage is closed to the voltage boundary. In this case, the currents will naturally drop as there is no voltage margin left to support the amount of current. During this condition where target currents are not satisfying the voltage boundary, the input error of the controller cannot be compensated within the next PWM cycle. This causes that the integration wind-up of the controllers will saturate and the controller will fail. Equation (4) and (5) can theoretically

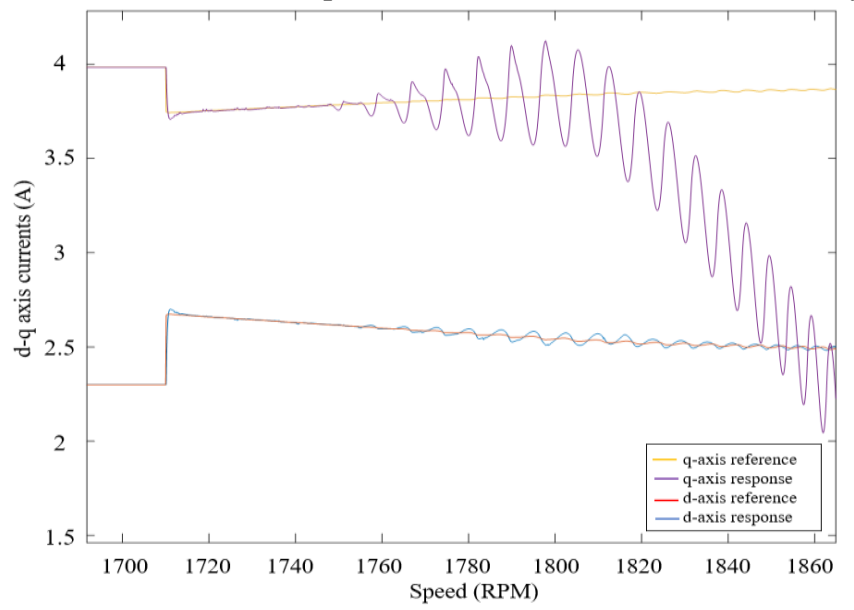

(a)

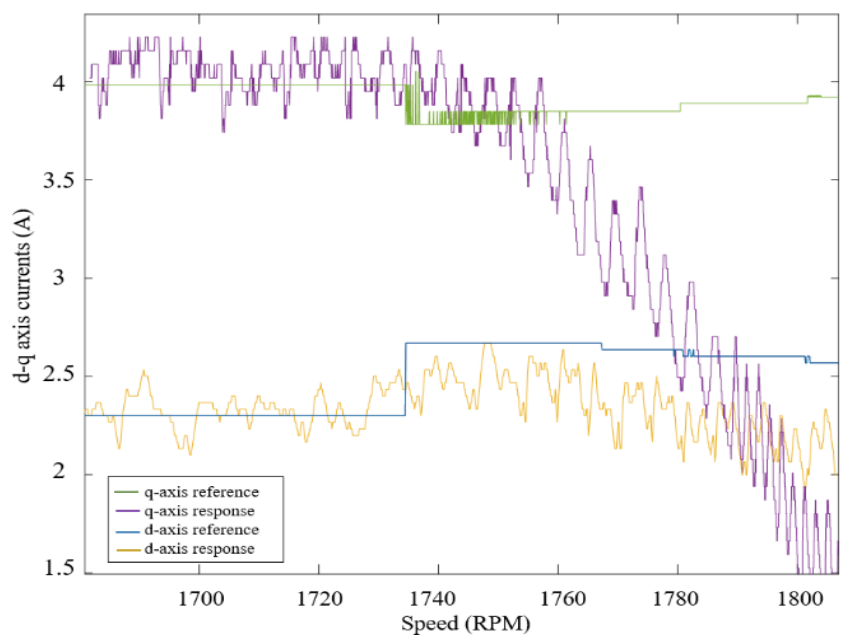

(b)

Fig. 13. The performance of the current controllers with a constant d-axis current in each electrical cycle (a) Simulation result (b) Experimental result explain the natural drop in motor current when the required stator voltage cannot be compensated by the available DC-link voltage. This eventually produces high current ripples causing PI controllers to saturate, resulting in high torque ripples. Furthermore, continuing applying inferior $i_{d s}^{e *}$, the current controllers will lose their stability and eventually fail.

As higher inverter output voltage is attained by applying the proposed method, higher torque and power are achieved for a given speed in comparison with conventional model-based algorithm (i.e. Fig. 14), as explained in Section I. As shown in Fig. $8 b$, the output torque and power as a function of speed are captured by Magtrol software, which is connected to torque transducer. The small difference between experimental and calculated torque (Fig. 14 (a) and Fig.7) is due to wind age and friction losses.

\section{CONCLUSION}

An IM propelling an electric vehicle at high speed operates in the field weakening region. This region is known for torque limitations.

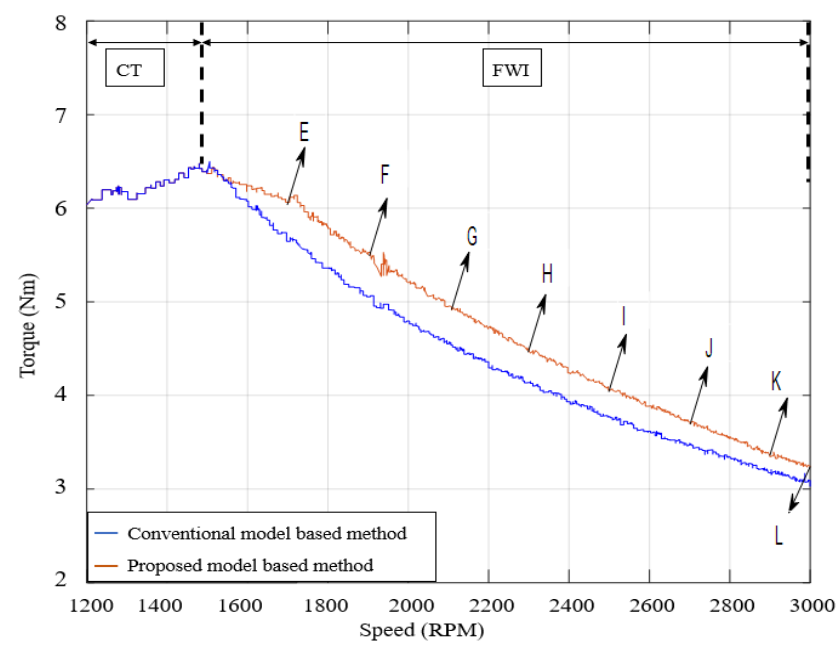

(a)

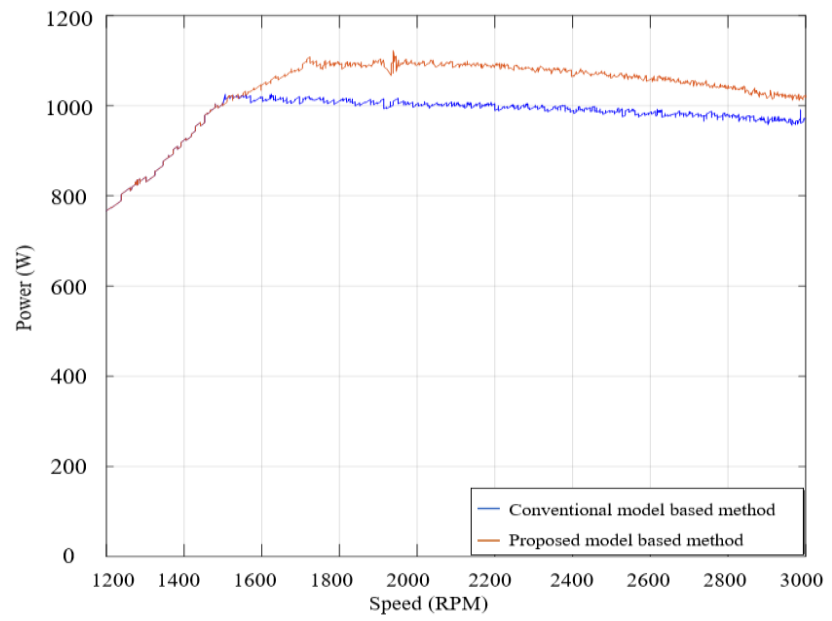

(b)

Fig. 14. Experimental comparison of proposed method and conventional model-based control. (a) Torque speed curve. (b) Power speed curve 
In this paper, a new model-based method is presented to increase the torque at the field weakening region. Increasing the torque at field weakening results in expanding torque-speed envelope without requiring hardware modification. The reference d-axis current signals are calculated based on the hexagonal voltage boundary and the stator voltage vector position. With this new proposed reference current waveform, the output torque and power of the IM are increased. This proposed method also remains stability of the current controllers as the result of the parabolic variation in amplitude of the d-axis current. This means that sufficient $d$-axis voltage is available, avoiding the natural drop of motor currents, and consequently reducing the torque ripples. Furthermore, the algorithm recognizes the beginning of the field weakening and matches the starting values of reference currents in this region with the desired currents in constant torque area. As a result, the calculation of the base speed is not required and smooth transition from the constant torque region to the constant power region is achieved. The feasibility of the proposed method is confirmed, analytically, by simulation and experimentally.

\section{APPENDIX}

The Appendix demonstrates the main difference of $d-q$ axis components and modulation index in normal SVM, SVM with

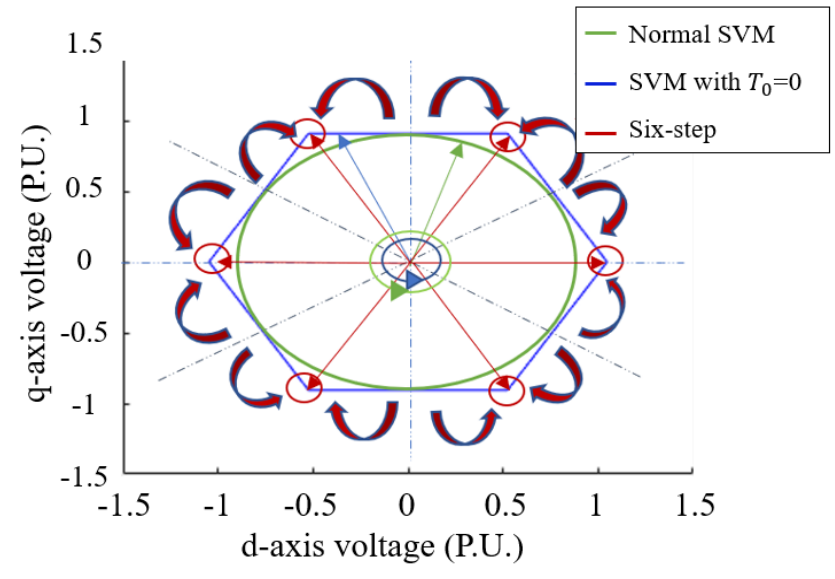

(a)

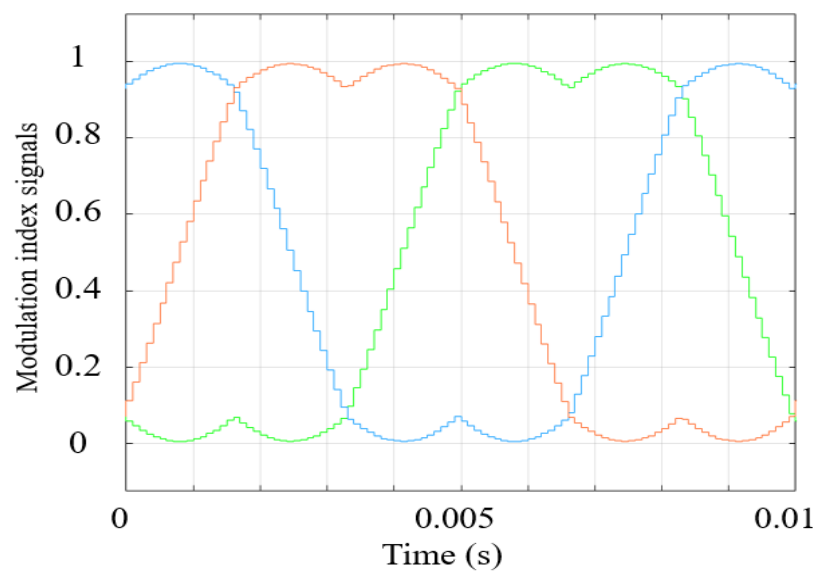

(b)

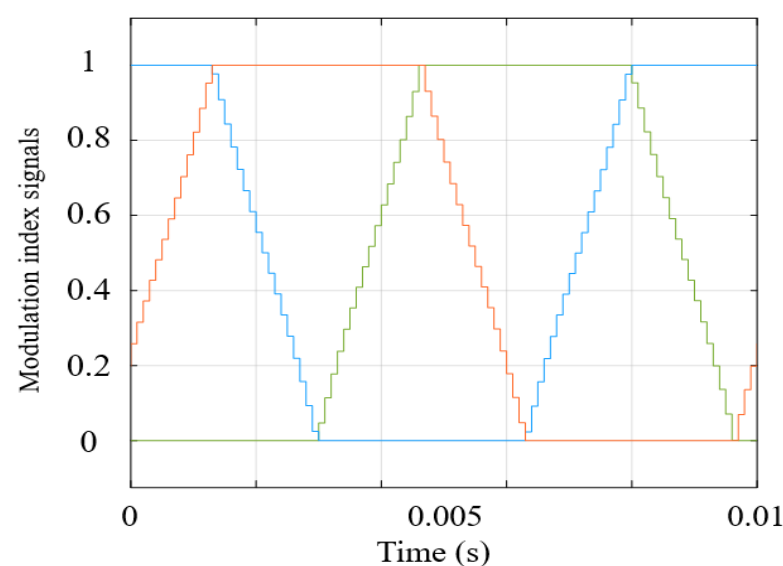

(c)

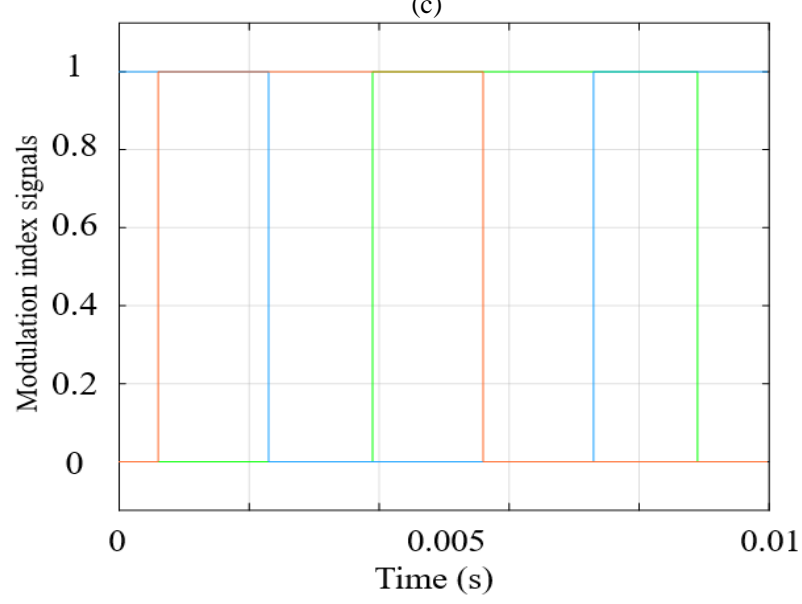

(d)

Fig. 15 (a) Position of stator voltage vector in different modulation techniques and modulation index signals in (b) SVM (c) SVM with $T_{0}=0$ (d) Six-step

$T_{0}=0$ and six-step modulation. As shown in Fig. 15a, the maximum value of stator voltage vector sits on inscribed voltage circle of hexagonal voltage boundary in normal operation of SVM. The more voltage can be utilised from SVM technique, when the null time $T_{0}$ of zero vectors is hold on zero by pushing the stator voltage around the hexagonal boundry. It should be noted that, the stattor voltage vector is still rotating along the boundry when $T_{0}$ is hold on zero. However in six-step opration, the stator voltage angle is hold only on the edges of the voltage boundry it can provide the fully utilisation of dclink voltage. The change in modulation index signals from nearly sinosoidal waveforms in SVM to complete squre vaweforms in six-step modulation are demostrated in Fig .15b to d.

To better understanding of the difference between these methods, the d-q axis components and the position of stator voltage vector with $100 \mathrm{~Hz}$ frequency are demonstrated in Fig. 16. As can be realised from Fig. 16 a1 and 16 a2, the voltage vector is continuously rotating around the inscribed circle inside of hexagonal voltage boundary. As stator voltage is increasing and $T_{0}$ becomes zero, the voltage vector reaches to hexagonal voltage boundary and stator voltage vector is still rotating along it. This causes that the $\mathrm{d}-\mathrm{q}$ axis component of stator voltage vector are changed from Fig. 16a1 to Fig. 16.b1. 
It should be mentioned that per-unit values in those figures are provided by having $\frac{2 V_{d c}}{\pi}$ as the maximum voltage. The $\frac{2 V_{d c}}{\pi}$ is the fundamental voltage component which can be achieved by six-step modulation. As shown in Fig. 16c1 and Fig. 16c2, the $d-q$ axis of stator voltage vector is discontinuous as the result of holding the stator voltage angle in edges points of hexagonal voltage boundary. Fig. 15a shows how the voltage vector is hold on a specific edge as the result of position of

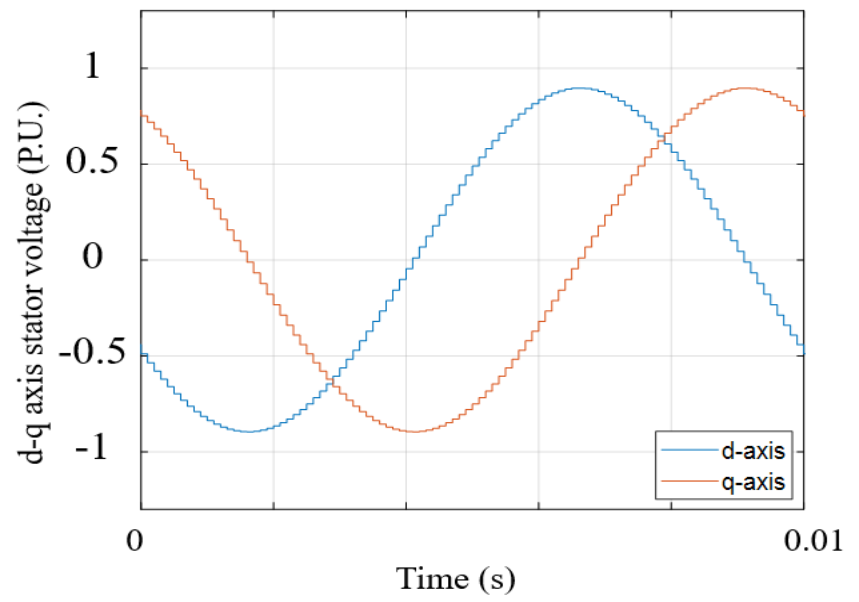

(a1)

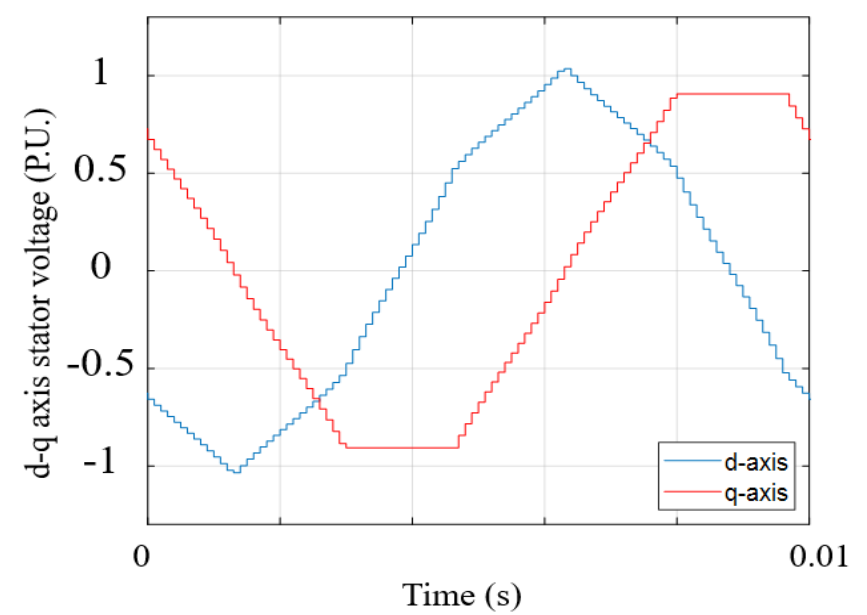

(b1)

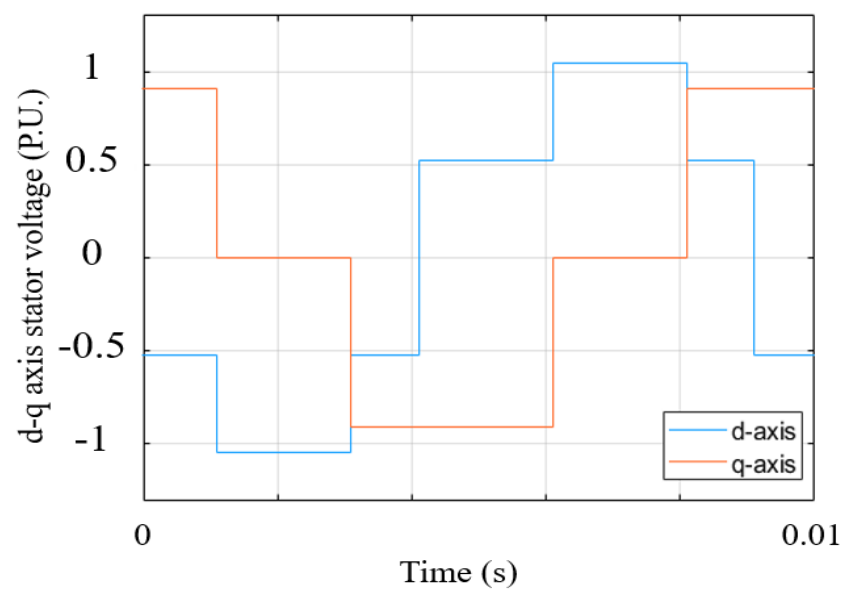

(c1)

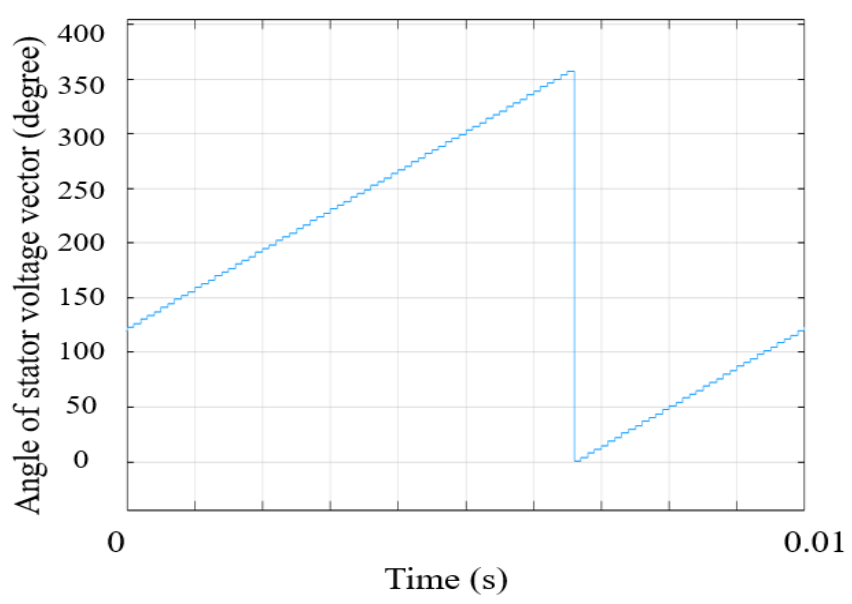

(a2)

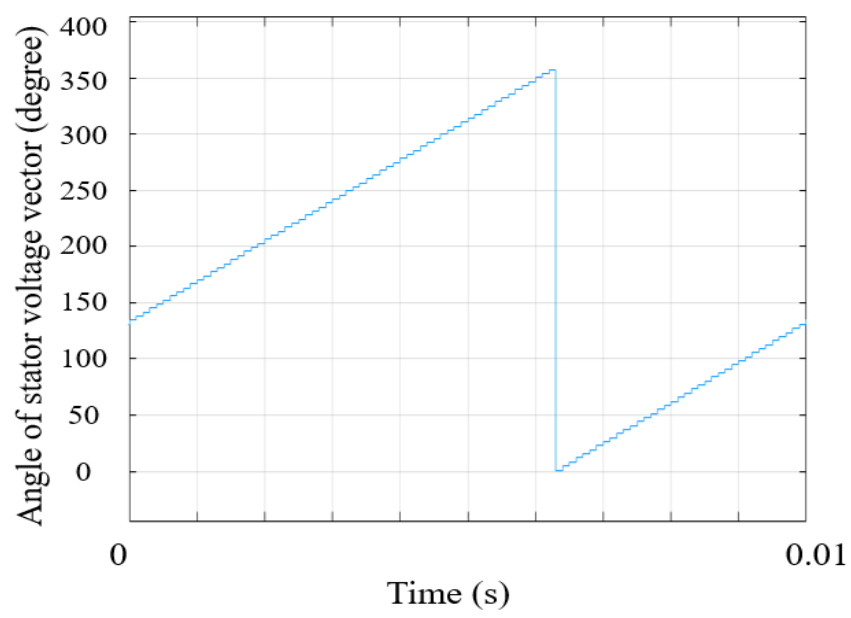

(b2)

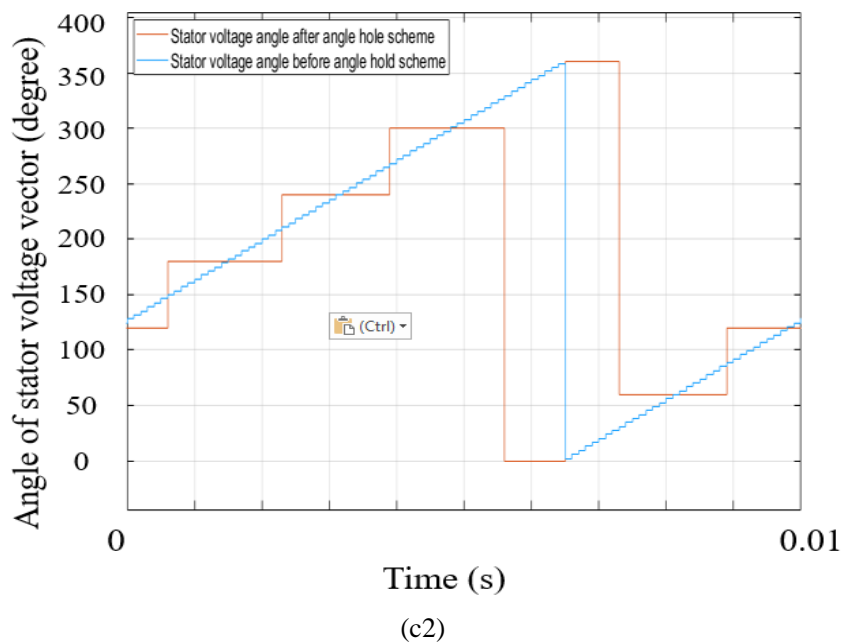

Fig. $16 \mathrm{~d}-\mathrm{q}$ axis components and position of stator voltage vector in different modulation (a1, a2) SVM (b1, b2) SVM with $T_{0}=0$ (c1, c2) sixstep

stator voltage vector. As an example, when the stator voltage vector is in 20 degree, then the angle hold mechanism holds the angle on 0 degree. As stator voltage vector goes to 40 degree, then the angle hold mechanism holds the angle in 60 degree. 


\section{REFERENCES}

H. Grotstollen and J. Wiesing, "Torque capability and control of a saturated induction motor over a wide range of flux weakening," IEEE Transactions on Industrial Electronics, vol. 42, pp. 374-381, 1995.

[2] M.-H. Shin, D.-S. Hyun, and S.-B. Cho, "Maximum torque control of stator-flux-oriented induction machine drive in the field-weakening region," IEEE Transactions on Industry Applications, vol. 38, pp. 117-122, 2002.

[3] G. H. B. Foo and X. Zhang, "Robust direct torque control of synchronous reluctance motor drives in the field-weakening region," IEEE Transactions on Power Electronics, vol. 32, pp. 1289-1298, 2017.

[4] X. Xu and D. W. Novotny, "Selection of the flux reference for induction machine drives in the field weakening region," IEEE transactions on industry applications, vol. 28, pp. 1353-1358, 1992.

[5] S. Bozhko, S. Dymko, S. Kovbasa, and S. M. Peresada, "Maximum Torque-per-Amp Control for Traction IM Drives: Theory and Experimental Results," IEEE Transactions on Industry Applications, vol. 53, pp. 181-193, 2017.

[6] K. Sang-Hoon and S. Seung-Ki, "Maximum torque control of an induction machine in the field weakening region," IEEE Transactions on Industry Applications, vol. 31, pp. 787-794, 1995.

[7] X. Xu, R. De Doncker, and D. W. Novotny, "A stator flux oriented induction machine drive," in Power Electronics Specialists Conference, 1988. PESC'88 Record., 19th Annual IEEE, 1988, pp. 870-876.

[8] A. Tripathi, A. M. Khambadkone, and S. K. Panda, "Dynamic control of torque in overmodulation and in the field weakening region," IEEE Transactions on Power Electronics, vol. 21, pp. 1091-1098, 2006.

[9] S.-H. Kim and S.-K. Sul, "Voltage control strategy for maximum torque operation of an induction machine in the field-weakening region," IEEE Transactions on Industrial Electronics, vol. 44, pp. 512-518, 1997.

[10] M. Mengoni, L. Zarri, A. Tani, G. Serra, and D. Casadei, "A comparison of four robust control schemes for field-weakening operation of induction motors," IEEE Transactions on Power Electronics, vol. 27, pp. 307-320, 2012.

[11] P.-Y. Lin and Y.-S. Lai, "Novel voltage trajectory control for field-weakening operation of induction motor drives," IEEE Transactions on Industry Applications, vol. 47, pp. 122-127, 2011.

[12] P.-Y. Lin and Y.-S. Lai, "Voltage control technique for the extension of DC-link voltage utilization of finitespeed SPMSM drives," IEEE Transactions on Industrial Electronics, vol. 59, pp. 3392-3402, 2012.

[13] O. Wasynczuk, S. D. Sudhoff, K. A. Corzine, J. L. Tichenor, P. C. Krause, I. G. Hansen, et al., "A maximum torque per ampere control strategy for induction motor drives," IEEE Transactions on Energy Conversion, vol. 13, pp. 163-169, 1998.

[14] K. H. Nam, AC Motor Control and Electrical Vehicle Applications: Taylor \& Francis, 2010.

[15] S.-H. Song, J.-W. Choi, and S.-K. Sul, "Transient torque maximizing strategy of induction machine in field weakening region," in Power Electronics Specialists Conference, 1998. PESC 98 Record. 29th Annual IEEE, 1998, pp. 1569-1574.

[16] J.-K. Seok and S. Kim, "Hexagon Voltage Manipulating Control (HVMC) for AC Motor Drives Operating at Voltage Limit," IEEE Transactions on Industry Applications, vol. 51, pp. 3829-3837, 2015.

[17] S. Morimoto, M. Sanada, and Y. Takeda, "Effects and compensation of magnetic saturation in fluxweakening controlled permanent magnet synchronous motor drives," IEEE Transactions on Industry Applications, vol. 30, p. 1632, 1994.

[18] H. A. Toliyat, E. Levi, and M. Raina, "," IEEE transactions on Energy conversion, vol. 18, pp. 271283, 2003.

[19] B. Cheng and T. R. Tesch, "Torque feedforward control technique for permanent-magnet synchronous motors," IEEE Transactions on Industrial Electronics, vol. 57, pp. 969-974, 2010.

[20] G. Gallegos-López, F. S. Gunawan, and J. E. Walters, "Current control of induction machines in the fieldweakened region," IEEE Transactions on Industry Applications, vol. 43, pp. 981-989, 2007.

[21] L. Harnefors, K. Pietilainen, and L. Gertmar, "Torquemaximizing field-weakening control: design, analysis, and parameter selection," IEEE Transactions on Industrial Electronics, vol. 48, pp. 161-168, 2001.

[22] Y. Liu, J. Zhao, R. Wang, and C. Huang, "Performance improvement of induction motor current controllers in field-weakening region for electric vehicles," IEEE Transactions on Power Electronics, vol. 28, pp. 24682482, 2013.

[23] Z. Dong, Y. Yu, W. Li, B. Wang, and D. Xu, "FluxWeakening Control for Induction Motor in Voltage Extension Region: Torque Analysis and Dynamic Performance Improvement," IEEE Transactions on Industrial Electronics, vol. 65, pp. 3740-3751, 2018.

[24] S.-Y. Jung, C. C. Mi, and K. Nam, "Torque control of IPMSM in the field-weakening region with improved DC-link voltage utilization," IEEE Transactions on Industrial Electronics, vol. 62, pp. 3380-3387, 2015.

[25] S. K. Sahoo and T. Bhattacharya, "Field Weakening Strategy for a Vector-Controlled Induction Motor Drive Near the Six-Step Mode of Operation," IEEE Transactions on Power Electronics, vol. 31, pp. 30433051, 2016.

[26] D. Casadei, M. Mengoni, G. Serra, A. Tani, and L. Zarri, "A control scheme with energy saving and DClink overvoltage rejection for induction motor drives of electric vehicles," IEEE Transactions on Industry Applications, vol. 46, pp. 1436-1446, 2010. 
[27] S. Bolognani and M. Zigliotto, "Novel digital continuous control of SVM inverters in the overmodulation range," IEEE Transactions on Industry Applications, vol. 33, pp. 525-530, 1997.

[28] J. Holtz, W. Lotzkat, and A. M. Khambadkone, "On continuous control of PWM inverters in the overmodulation range including the six-step mode," IEEE transactions on power electronics, vol. 8, pp. 546-553, 1993.

[29] A. M. Hava, S.-K. Sul, R. J. Kerkman, and T. A. Lipo, "Dynamic overmodulation characteristics of triangle intersection PWM methods," IEEE Transactions on Industry Applications, vol. 35, pp. 896-907, 1999.

[30] S. M. Gadoue, D. Giaouris, and J. Finch, "Tuning of PI speed controller in DTC of induction motor based on genetic algorithms and fuzzy logic schemes," in Proceedings of the 5th International Conference on Technology and Automation, 2005: Citeseer, pp. 8590.

[31] H. Gashtil, V. Pickert, D. Atkinson, D. Giaouris, and M. Dahidah, "A Case Study of Real Time Implementation of Extended Kalman Filter in Dual Core DSP for The On-line Estimation of Induction Machine Parameters," in 2019 IEEE 13th International Conference on Compatibility, Power Electronics and Power Engineering (CPEPOWERENG), 2019: IEEE, pp. 1-7. 